\title{
T-Cell Receptor Activation Decreases Excitability of Cortical Interneurons by Inhibiting $\alpha 7$ Nicotinic Receptors
}

\author{
Pragya Komal, ${ }^{1}$ Geoff Gudavicius, ${ }^{2}$ Christopher J. Nelson, ${ }^{2}$ and Raad Nashmi ${ }^{1}$ \\ ${ }^{1}$ Department of Biology and ${ }^{2}$ Department of Biochemistry and Microbiology, University of Victoria, Victoria, British Columbia, V8W 3N5, Canada
}

\begin{abstract}
Many proteins in the immune system are also expressed in the brain. One such class of immune proteins are T-cell receptors (TCRs), whose functions in T lymphocytes in adaptive immunity are well characterized. In the brain, TCRs are confined to neocortical neurons, but their functional role has not been determined. In mouse layer 1 neocortical neurons, TCR activation inhibited $\alpha 7$ nicotinic currents. TCRs modulated $\alpha 7$ currents via tyrosine phosphorylation of $\alpha 7$ nicotinic receptors (nAChRs) through src tyrosine kinases because eliminating lck kinase expression, coexpressing fyn kinase dead, or mutating tyrosine to alanine in $\alpha 7$ blocked the effect of TCR activation. We found that TCR stimulation decreased surface $\alpha 7 \mathrm{nAChRs}$ and reduced single-channel conductance. These results reveal that TCRs play a major role in the modulation of cholinergic neurotransmission in the brain mediated by $\alpha 7 \mathrm{nAChRs}$ and that this has a profound effect on regulating neuronal excitability.
\end{abstract}

\section{Introduction}

The CNS has been regarded as an immune privileged organ because of the blood-brain barrier and an immunosuppressive microenvironment (Sallusto et al., 2012). However, there is evidence that immune proteins, such as MHC, cytokines, and T-cell receptor (TCR) subunits, originally thought to have only immune function, are also expressed in CNS neurons (Boulanger et al., 2001; Syken and Shatz, 2003). TCRs are known for their role in adaptive immunity on T lymphocytes (Irvine et al., 2002), but this restrictive role in only immune system function has recently been challenged. TCR expression in the adult brain is restricted to the neocortex (Syken and Shatz, 2003). The TCR is an octameric complex of subunits where the $\alpha \beta$ subunits bind to the peptide/MHC complex (Huang and Wange, 2004). T-cell antigen receptor $\beta$ (TCR $\beta$ ) along with MHC class I and $\mathrm{CD} 3 \zeta$ are expressed in neurons, with the latter two proteins known to play a role in the induction of synaptic plasticity (Baudouin et al., 2008; EscandeBeillard et al., 2010). However, there is no reported evidence

Received May 16, 2013; revised Nov. 4, 2013; accepted Nov. 7, 2013.

Author contributions: P.K., C.J.N., and R.N. designed research; P.K. and G.G. performed research; P.K., G.G., and R.N. analyzed data; P.K., G.G., C.J.N., and R.N. wrote the paper.

This work was supported by a Natural Sciences and Engineering Research Council of Canada Discovery grant, a Heart and Stroke Foundation of Canada grant, a National Alliance for Research on Schizophrenia and Depression Young Investigator Award to R.N., the Victoria Foundation-Myre and Winifred Sim Fund, a Canadian Foundation for Innovation grant, the British Columbia Knowledge Development Fund, and a Natural Sciences and Engineering Research Council of Canada Research Tools and Instrumentation grant. We thank Dr. Kerry Delaney, Dr. Perry Howard, and Anthony Renda for helpful discussions; Dr. Bruce N. Cohen for technical advice on single-channel recordings; Dr. Barbara J. Morley (Boys Town National Research Hospital, Omaha, NE) for technical advice for $\alpha 7$-null mice husbandry; Zhiwei Shi and Qi Huang for excellent technical assistance; and Ariel Sullivan, Christina Barnes, Kristin Vandeloo, Carl Jensen, and all other members of the mouse facility at the University of Victoria for providing excellent care of our mice.

The authors declare no competing financial interests.

Correspondence should be addressed to Dr. Raad Nashmi, University of Victoria, Department of Biology, P0 Box 3020, Station CSC, Victoria, British Columbia V8W 3N5, Canada. E-mail: raad@uvic.ca.

DOI:10.1523/JNEUROSCI.2093-13.2014

Copyright $\odot 2014$ the authors $\quad 0270-6474 / 14 / 340022-14 \$ 15.00 / 0$ that TCRs can modify activity of any ligand-gated ion channel in the CNS. The earliest activated kinases after TCR stimulation are downstream src family kinases (Weiss and Littman, 1994).

$\alpha 7$ nicotinic acetylcholine receptors (nAChRs) are members of the pentameric cys loop family of ligand-gated ion channels. These receptors constitute the high-affinity $\alpha$-bungarotoxin $(\alpha$-BTX) binding sites in the CNS and are the second most prevalent nAChR subtype in the CNS after $\alpha 4 \beta 2$ (Chen and Patrick, 1997). $\alpha 7 \mathrm{nAChRs}$ play an important role in cognition, such as attention and memory (Levin et al., 2006; Young et al., 2007). These receptors are expressed most abundantly in the hippocampus and neocortex (Freedman et al., 1993; Christophe et al., 2002). The long intracellular loop between the third and fourth membrane-spanning regions of each $\alpha 7$ subunit contains putative protein kinase phosphorylation sites, including at least one tyrosine phosphorylation site (Charpantier et al., 2005). Tyrosine phosphorylation of $\alpha 7$ nicotinic receptors is known to modulate their activity (Charpantier et al., 2005; Cho et al., 2005).

Because $\alpha 7 \mathrm{nAChRs}$ and TCRs are both highly expressed in the cerebral cortex and TCRs can signal via tyrosine kinases, this opens the possibility that TCRs can have downstream effects on $\alpha 7$ nAChRs. We examined whether TCR activation can modulate $\alpha 7$ nAChRs in CNS neurons. We provide evidence that TCR activation inhibits $\alpha 7$ currents in cortical neurons. The negative modulatory effect of TCRs on $\alpha 7 \mathrm{nAChR}$ activity is mediated through activation of fyn and lck tyrosine kinases and the subsequent tyrosine phosphorylation of the cytoplasmic loop of $\alpha 7$. The TCR-negative regulation of $\alpha 7$ receptors was due to a loss of surface $\alpha 7$ receptors and a decrease in $\alpha 7$ single-channel conductance. Furthermore, we found that TCR activation decreased the excitability of neurons. Together, our results reveal a novel mechanism of modulation of neuronal excitability by altering ion channel function through phosphorylation mediated by activation of an immune receptor. 


\section{Materials and Methods}

cDNA constructs. Mouse $\alpha 7 \mathrm{nAChR}$ and human RIC- 3 cDNA plasmids were kindly provided by Dr. Jerry Stitzel (University of Colorado Boulder, Boulder, CO) and Dr. Neil Millar (University of London, London, UK), respectively. RIC-3 is a chaperone protein that is a requirement for the functional expression of $\alpha 7 \mathrm{nAChRs}$ in many mammalian cell lines (Lansdell et al., 2005). Venus fluorescent protein was generously provided by Atsushi Miyawaki (Riken Brain Science Institute, Wako-shi, Saitama, Japan) (Nagai et al., 2002). We constructed a cDNA construct in which Venus fluorescent protein and hemagglutinin epitope tag were fused to $\alpha 7 \mathrm{nAChR}$ in the M3-M4 cytoplasmic loop ( $\alpha 7$-Venus) and functions normally in every respect (Dau et al., 2013).

According to ProSite analysis, there is a single putative tyrosine kinase phosphorylation site in the M3-M4 cytoplasmic region of $\alpha 7$ at Y442. Using gene synthesis approach (Bioscience), the wild-type (WT) tyrosine 442 codon (TAC) was mutated to the alanine codon (GCT) in both $\alpha 7$ $(\alpha 7(\mathrm{Y} 442 \mathrm{~A}))$ and $\alpha 7$-Venus ( $\alpha 7$ (Y442A)Venus).

Expression vectors for constitutively active fyn kinase (FKA) and fyn kinase dead construct (FKD) were kindly provided by Dr. Todd Holmes (New York University, New York, NY) (Nitabach et al., 2002).

Cell culture and transfection. In this study, we cultured Jurkat cells (clone E6-1, catalog \#TIB-152, ATCC). Jurkat cells are a clonal T lymphocyte cell line, which natively expresses TCRs. Other Jurkat cells used in the study include the Jurkat TCR $\beta$ subunit knock-out (KO), in which there is loss of expression of the $\beta$ subunit of the TCR (clone J.RT3-T3.5, catalog \#TIB-153, ATCC) and the Jurkat lck KO cells, in which the cells are deficient in lck tyrosine kinase activity (JCaM 1.6, catalog \#CRL-2063, ATCC). Jurkat cells were maintained in RPMI 1640 medium supplemented with $10 \% \mathrm{FBS}$, penicillin $(100 \mathrm{U} / \mathrm{ml})$, streptomycin $(100 \mu \mathrm{g} / \mathrm{ml})$, and $5 \%$ glutamine in a humidified $\mathrm{CO}_{2}$ incubator at $37^{\circ} \mathrm{C}$.

We transiently transfected Jurkat cells using electroporation. On the day of electroporation, inside $35 \mathrm{~mm}$ Petri dishes, we coated 5-mmdiameter round glass coverslips (catalog \#64-0700, Warner) with rat collagen Type $1(0.05 \mathrm{mg} / \mathrm{ml}$, catalog \#92590, Millipore) for $3 \mathrm{~h}$ and washed twice with PBS, $\mathrm{pH}$ 7.4. In an electroporation cuvette (catalog \#165-2088, Bio-Rad), $1 \times 10^{7}$ Jurkat cells were incubated with $6 \mu \mathrm{g}$ of $\alpha 7$ nAChR cDNA, $6 \mu \mathrm{g}$ of RIC-3 cDNA, and $0.6 \mu \mathrm{g}$ of soluble Venus fluorescent protein cDNA, in $300 \mu$ l of incomplete RPMI 1640 medium and subjected to electroporation with a Gene Pulser Xcell (Bio-Rad) at $250 \mathrm{~V}$ and $960 \mu \mathrm{F}$. RPMI-1640 incomplete medium was identical to RPMI1640 complete medium, except that FBS was omitted. Electroporated cells were then plated into the $35 \mathrm{~mm}$ dishes each containing $2.5 \mathrm{ml}$ complete RPMI media. Whole-cell patch-clamp recordings were performed $2 \mathrm{~d}$ after electroporation. For experiments involving confocal imaging of cells, the Jurkat cells were plated onto collagen Type 1-coated coverslip bottom $35 \mathrm{~mm}$ dishes (catalog \#P35G-0-14-C, MatTek).

HEK293T cells were also used in the study. They were grown in DMEM high glucose medium supplemented with 10\% FBS, $2 \mathrm{~mm}$ L-glutamine, $100 \mathrm{U} / \mathrm{ml}$ penicillin, and $100 \mu \mathrm{g} / \mathrm{ml}$ streptomycin (DMEM complete medium) and maintained in a $\mathrm{CO}_{2}$ incubator at $37^{\circ} \mathrm{C}$. Three to $6 \mathrm{~d}$ before electrophysiological recordings, the cells were incubated with trypsin for $3 \mathrm{~min}$, mechanically dissociated, and seeded onto poly-DLlysine $(1 \mathrm{mg} / \mathrm{ml}$, catalog \#P9011, Sigma) coated $5 \mathrm{~mm}$ glass coverslips (catalog \#64-0700, Warner) placed inside 35-mm-diameter Petri dishes. Cells were transfected at 60-70\% confluency using Fugene Transfection Reagent (catalog \#PRE2311, Promega). To each dish, $2 \mu \mathrm{g}$ of $\alpha 7 \mathrm{nAChR}$ cDNA, $2 \mu \mathrm{g}$ of RIC-3 cDNA, and $0.2 \mu \mathrm{g}$ of soluble Venus fluorescent protein cDNA were mixed with $3 \mu \mathrm{l}$ of Fugene transfection reagent and $250 \mu \mathrm{l}$ of incomplete DMEM medium, which was identical to the complete DMEM, except lacking FBS. Transfection was performed according to the manufacturer's protocol. Electrophysiological recordings were performed 2-3 d after transfection.

Whole-cell patch-clamp recordings from cultured cells. Cells were visualized with differential interference contrast illumination using an upright microscope (Nikon FN1) equipped with a CFI APO $40 \times$ W NIR objective ( 0.80 numerical aperture, $3.5 \mathrm{~mm}$ working distance). Transfected cells were identified with Venus fluorescent protein under fluorescence illumination with a mercury lamp. Standard whole-cell recordings were performed using a Multiclamp 700B amplifier (Molecular Devices) low pass filtered at $4 \mathrm{kHz}$ and digitized at $10 \mathrm{kHz}$ with a Digidata $1440 \mathrm{~A}$ (Molecular Devices). Whole-cell patch-clamp recordings were performed using extracellular solution containing the following (in $\mathrm{mM}$ ): $150 \mathrm{NaCl}, 4 \mathrm{KCl}, 2 \mathrm{CaCl}_{2}, 2 \mathrm{MgCl}_{2}, 10 \mathrm{HEPES}$, and $10 \mathrm{D}$-glucose adjusted to $\mathrm{pH}$ 7.4. Micropipette recording electrodes were pulled from borosilicate glass of $1.5 \mathrm{~mm}$ OD and $1.0 \mathrm{~mm}$ ID (catalog \#1B150F-4, WPI) on a P-97 Flaming/Brown micropipette puller (Sutter Instruments). Patch electrodes (7-9 $\mathrm{M} \Omega$ ) were filled with pipette solution containing the following (in mM): $108 \mathrm{KH}_{2} \mathrm{PO}_{4}, 4.5 \mathrm{MgCl}_{2}, 0.9$ EGTA, 9 HEPES, $0.4 \mathrm{CaCl}_{2}$, 14 creatine phosphate (Tris salt), $4 \mathrm{Mg}$-ATP, 0.3 GTP (Tris salt), pH 7.4 with $\mathrm{KOH}$. Atropine (100 nM) was present in the bath throughout all recordings to block muscarinic acetylcholine receptor responses. Series resistance was compensated $50 \%$, and the membrane potential was held at $-60 \mathrm{mV}$. Holding potentials were corrected for the liquid junction potential. ACh was delivered for $1 \mathrm{~s}$ duration using the two-barrel glass $\theta$ tube valve driven drug applicator, which was positioned $\sim 300 \mu \mathrm{m}$ from the recorded cell (Komal et al., 2011). Solution exchange rates measured from open tip junction potential changes during application with $10 \%$ extracellular solution were typically $<500 \mu \mathrm{s}$ ( $10-90 \%$ peak time). The timing of agonist delivery and recordings was controlled using pCLAMP 10.2 acquisition software (Molecular Devices).

Whole-cell patch-clamp recordings from brain slices. All experiments on mice were performed in accordance of the Canadian Council of Animal Care and approved by the Animal Care Committee of the University of Victoria. WT C57BL/6J mice, TCR $\beta$ subunit KO mice (strain B6.129P2-

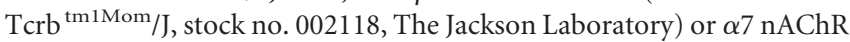
KO mice (strain B6.129S7-Chrna7 ${ }^{\text {tm 1 Bay }} / \mathrm{J}$, stock no. 003232, The Jackson Laboratory) at 10 to $15 \mathrm{~d}$ postnatal of either sex were anesthetized with isofluorane and decapitated. Subsequently, the brain was rapidly removed, kept for a minute in slicing solution, and sectioned coronally into $320 \mu \mathrm{m}$ thick slices in oxygenated slicing solution with a vibratome (Leica 1000S). Slicing solution comprised of (in mM): 250 sucrose, 2.5 $\mathrm{KCl}, 1.2 \mathrm{NaH}_{2} \mathrm{PO}_{4}, 1.3 \mathrm{MgCl}_{2}, 2.4 \mathrm{CaCl}_{2}, 26 \mathrm{NaHCO}_{3}$, and $11 \mathrm{D}$-glucose. Slices were transferred and incubated in a $37^{\circ} \mathrm{C}$ water bath for $1 \mathrm{~h}$. Concanavilin A (ConA) $(75 \mu \mathrm{g} / \mathrm{ml})$ incubation time of 30 min was used for all our experiments. Slices were continuously bubbled in $95 \% \mathrm{O}_{2}$ and $5 \%$ $\mathrm{CO}_{2}$ during incubation and recording.

Using infra-red video-assisted differential interference contrast illumination in combination with an upright microscope (Nikon FN1) equipped with a CFI APO $40 \times$ W NIR objective ( 0.80 numerical aperture, $3.5 \mathrm{~mm}$ working distance), whole-cell patch-clamp recordings were performed on layer 1 medial prefrontal cortical neurons from C57BL/6J mice (WT) and TCR $\beta$ KO mice. Data were acquired using a Multiclamp 700B amplifier (Molecular Devices), low-pass filtered at $4 \mathrm{kHz}$, and digitized at $10 \mathrm{kHz}$ with a Digidata $1440 \mathrm{~A} \mathrm{~A} / \mathrm{D}$ converter. Brain slices were perfused continuously with extracellular solution comprised of the following (in mM): $125 \mathrm{NaCl}, 2.5 \mathrm{KCl}, 1.2 \mathrm{NaH}_{2} \mathrm{PO}_{4}, 1.3 \mathrm{MgCl}_{2}, 2.4 \mathrm{CaCl}_{2}$, $26 \mathrm{NaHCO}_{3}$, and $11 \mathrm{D}$-glucose. Neurons were visualized with an upright microscope (Nikon FN1) equipped with a CFI APO 40× W NIR objective ( 0.80 numerical aperture, $3.5 \mathrm{~mm}$ working distance) using infra-red differential interference contrast and a video camera (IR-1000, Dage MTI). The patch electrodes had resistances between 9 and $11 \mathrm{~m} \Omega$ when filled with pipette solution containing the following (in $\mathrm{mM}$ ): 130 potassium gluconate, 5 EGTA, $0.5 \mathrm{CaCl}_{2}, 2 \mathrm{MgCl}_{2}, 10$ HEPES, $3 \mathrm{Mg}$-ATP, 0.2 GTP, and 5 phosphocreatine Tris, $\mathrm{pH}$ adjusted to 7.4 with $\mathrm{KOH}$, osmolarity adjusted to $300 \mathrm{mOsm}$ with sucrose. Whole-cell voltage-clamp recordings were performed at room temperature with a MultiClamp 700B amplifier (Molecular Devices) and pCLAMP 10.2 software (Molecular Devices). Data were filtered at $4 \mathrm{kHz}$ and sampled at $10 \mathrm{kHz}$ with a Digidata 1440A data acquisition system (Molecular Devices). The membrane potential was corrected for liquid junction potential, and series resistance was corrected $50 \%$. Neurons were held at $-60 \mathrm{mV}$. The $\theta$ tube of the valve-driven drug applicator was positioned $\sim 600 \mu \mathrm{m}$ from the recorded cell, and $100 \mu \mathrm{M}$ PHA543613 hydrochloride (catalog \#3092, Tocris Bioscience), a specific agonist for $\alpha 7$ nicotinic receptor, was applied for $1 \mathrm{~s}$.

The firing frequency of layer 1 cortical neurons from brain slices of WT mice and TCR $\beta$ KO mice for untreated and ConA treatment $(75 \mu \mathrm{g} / \mathrm{ml}$, 
$30 \mathrm{~min}$ ) was measured in current-clamp mode of whole-cell configuration, with bridge balance correction. Methylycaconitine (MLA, $10 \mathrm{~nm}$ ) was used in control experiments to identify the contribution by $\alpha 7$ nicotinic receptors toward the firing rate of layer 1 neurons. Current-clamp steps ranging from $0 \mathrm{pA}$ to $200 \mathrm{pA}$ ( $500 \mathrm{~ms}$ duration) in $20 \mathrm{pA}$ increments were used to induce action potentials in cortical neurons. Firing frequency was calculated by dividing the number of action potentials by the $500 \mathrm{~ms}$ duration of each depolarizing step current. All data acquisition and analyses were performed using pClamp 10.2 software. Cells were not used for analysis if resting membrane potential $\left(\mathrm{V}_{\mathrm{m}}\right)$ was more depolarized than $-40 \mathrm{mV}$, access resistance $\left(\mathrm{R}_{\mathrm{a}}\right)>35 \mathrm{M} \Omega$, or input resistance $\left(\mathrm{R}_{\text {input }}\right)<100 \mathrm{~m} \Omega$.

Current fluctuation analysis to estimate single-channel conductance. Estimation of single-channel conductance of $\alpha 7$ nicotinic receptor was done by fluctuation analysis as previously described (Sigworth, 1980; Lambert et al., 1989; Gill et al., 1995; Brown et al., 1998). We used Clampfit 10.2 software (Molecular Devices) to conduct fluctuation analysis on the whole-cell current traces. Briefly, repeated whole-cell $\alpha 7$ currents evoked using $100 \mu \mathrm{M}$ PHA543613 hydrochloride from brain slices of mice held at $-60 \mathrm{mV}$ were obtained. The variance of the current at each sample point of each trace was plotted against the mean current of the averaged traces at the same sample point in time. Then a linear fit was performed through the sampled points. The slope of the fit estimated the unitary current, I, of the nicotinic ion channel. The single-channel conductance was calculated using the equation $\gamma=\mathrm{i} /\left(\mathrm{V}_{\mathrm{h}}-\mathrm{E}_{\text {rev }}\right)$ where, $\mathrm{V}_{\mathrm{h}}$ is the holding potential $(-60 \mathrm{mV})$ and $\mathrm{E}_{\text {rev }}$ is the reversal potential for $\alpha 7$ receptors, determined experimentally as $(-0.7 \mathrm{mV})$.

Single-channel recordings. Single-channel recordings in the cellattached patch-clamp configuration were performed at room temperature on WT Jurkat cells electroporated with mouse $\alpha 7 \mathrm{nAChR}$ receptor and RIC- 3 cDNA. The bath and pipette solutions contained the following (in mM): $150 \mathrm{NaCl}, 4 \mathrm{KCl}, 2 \mathrm{CaCl}_{2}, 2 \mathrm{MgCl}_{2}, 10$ HEPES, 10 D-glucose, and $10^{-4}$ atropine adjusted to $\mathrm{pH} 7.4$, with $100 \mu \mathrm{M}$ ACh dissolved in the pipette solution. Micropipette recording electrodes were $1.5 \mathrm{~mm}$ OD and $1.0 \mathrm{~mm}$ ID borosilicate glass (catalog \#1B150F-4, WPI) that were pulled on a P-97 Flaming/Brown micropipette puller (Sutter Instruments). The pulled pipettes were coated with Sylgard \#184 (Dow Corning) and fire polished. Recording micropipettes had resistances between 6 and $15 \mathrm{~m} \Omega$. A pipette holding potential $\left(\mathrm{V}_{\mathrm{p}}\right)$ of $60 \mathrm{mV}$ was used throughout the recordings. Because recordings were made in the cell-attached configuration, this meant that the membrane potential underneath the patch of membrane was hyperpolarized by $-60 \mathrm{mV}$ in addition to the resting membrane potential. Single-channel currents were acquired using a Multiclamp 700B amplifier (Molecular Devices), low-pass filtered at 4 $\mathrm{kHz}$, digitized at $50 \mathrm{kHz}$ with a Digidata $1440 \mathrm{~A} \mathrm{~A} / \mathrm{D}$ converter (Molecular Devices), and collected with pClamp 10.2 software.

Clampfit 10.2 software (Molecular Devices) was used to analyze single-channel recordings to determine single-channel amplitudes and gating kinetics. Single-channel recordings were notch-filtered at $60 \mathrm{~Hz}$ followed by $4 \mathrm{kHz}$ Gaussian filter. The "Event Detection-Single-Channel Search" feature in Clampfit was used to detect the open and closed channel events and analyzed for single-channel amplitudes and closed and open durations. Single-channel current amplitudes were analyzed by plotting an amplitude histogram fitted with two Gaussian functions: one Gaussian corresponded to the closed channel current level and the other corresponded to the open channel current level. Single-channel conductance was calculated in two ways. One way was dividing the singlechannel amplitude by the driving force $\gamma=\mathrm{i} /\left(\mathrm{V}_{\mathrm{h}}-\mathrm{E}_{\text {rev }}\right)$ where, $\mathrm{V}_{\mathrm{h}}$ was estimated to be $-108 \mathrm{mV}$ by taking an average of the resting membrane potentials recorded from whole-cell recordings from Jurkat cells $(-48$ $\mathrm{mV})$ minus the pipette potential $(60 \mathrm{mV})\left(\mathrm{V}_{\mathrm{h}}=\mathrm{V}_{\mathrm{m}}-\mathrm{V}_{\mathrm{p}}\right)$. Singlechannel conductance was also verified by calculating the slopes of current-voltage relationships of single-channel recordings stepped at various pipette potentials. To assess gating kinetics, open and closed duration histograms of single-channel events were graphed on a semilog plot and fit with functions with multiple.

Immunoprecipitation and Western blot analysis. Jurkat cells $\left(1 \times 10^{7}\right.$ cells $/ \mathrm{ml}$ ) were electroporated with $6 \mu \mathrm{g}$ of $\alpha 7$-Venus, $6 \mu \mathrm{g}$ of mouse RIC-3 in $300 \mu \mathrm{l}$ of incomplete RPMI media. $\alpha 7$-Venus contains both a
Venus fluorescent protein and an upstream HA epitope tag inserted into the M3-M4 cytoplasmic loop of the $\alpha 7 \mathrm{nAChR}$ subunit. Electroporated cells were then plated onto $35 \mathrm{~mm}$ dishes each containing $2.5 \mathrm{ml}$ complete RPMI media. On the second day after transfection, WT $\alpha 7$-Venus receptor-containing Jurkat cells were treated with control solution (RPMI solution) or ConA for $30 \mathrm{~min}$ at $37^{\circ} \mathrm{C}$. Before immunoprecipitation, cells were washed with ice-cold $\mathrm{PBS}(\mathrm{pH} 7.4)$ at $4^{\circ} \mathrm{C}$ and resuspended in $1 \mathrm{ml}$ freshly prepared immunoprecipitation buffer containing $50 \mathrm{~mm}$ Tris- $\mathrm{HCl} \mathrm{pH} 8,150 \mathrm{~mm} \mathrm{NaCl}, 0.5 \%$ NP40, 0.5\% Triton X-100, $0.5 \%$ sodium deoxycholate, $0.1 \%$ SDS, 1 mм EDTA, 2 mм sodium orthovanadate, $1 \mu \mathrm{g} / \mathrm{ml}$ pepstatin, $1 \mu \mathrm{g} / \mathrm{ml}$ leupeptin, $1 \mu \mathrm{g} / \mathrm{ml}$ aprotinin. The cells were lysed on ice for $10 \mathrm{~min}$ and clarified by centrifugation at $18,000 \times g$ for $5 \mathrm{~min}$. $\alpha 7$ receptors were immunoprecipitated using $2 \mu \mathrm{l}$ of anti-HA antibody (clone 12ca5, gift from Ivan Sadowski, University of British Columbia) and incubated with lysate for $1 \mathrm{~h}$ before addition of 20 $\mu \mathrm{l}$ of BSA blocked protein A/G agarose beads $(200 \mu \mathrm{g}$ BSA in $1 \mathrm{ml}$ immunoprecipitation buffer with beads) (catalog \#20422, Pierce) for an additional hour with rotation. Beads were washed 3 times in $1 \mathrm{ml}$ immunoprecipitation buffer, and immune complexes were released by briefly boiling in $25 \mu \mathrm{l}$ SDS loading buffer. Proteins were resolved by SDS-PAGE and transferred to nitrocellulose membrane. Western blotting was performed using anti-HA antibody (clone 12ca5) at 1:5000 dilution to detect total cellular $\alpha 7$ nicotinic receptors. Tyrosine phosphorylation of $\alpha 7$ receptors was detected with anti-phosphotyrosine antibodies (1:2000 dilution, clone 4G10, Millipore). HRP-conjugated anti-mouse secondary antibody (catalog \#NXA931, GE Healthcare) was used at 1:5000. Proteins were detected by chemiluminescence (GE Healthcare).

Surface $\alpha$-BTX labeling and spectral confocal microscopy. Jurkat cells were transfected with $6 \mu \mathrm{g}$ of mouse $\alpha 7$-Venus or $\alpha 7(\mathrm{Y} 442 \mathrm{~A})$-Venus $\mathrm{nAChR} c \mathrm{DNA}$ and $6 \mu \mathrm{g}$ of mouse RIC-3. For cell surface receptor expression assays, $48 \mathrm{~h}$ after transfection cells were incubated on ice for $1 \mathrm{~h}$ to ensure that the temperature was $<4^{\circ} \mathrm{C}$. ConA was incubated $(75 \mu \mathrm{g} / \mathrm{ml})$ for $30 \mathrm{~min}$ at $37^{\circ} \mathrm{C}$. Cells were then fixed with $4 \%$ paraformaldehyde in PBS for $10 \mathrm{~min}$ on ice and washed twice with ice-cold PBS. Surface $\alpha 7$ receptors were then labeled with Alexa Fluor $647 \alpha$-BTX (1:200, Fl-BTx, catalog \#B35450, Invitrogen) under nonpermeabilized conditions for $30 \mathrm{~min}$ and washed twice with ice-cold PBS. Then the cells were plated on rat tail collagen Type I-coated dishes before imaging $(0.05 \mathrm{mg} / \mathrm{ml}$, catalog \#92590, Millipore). Surface expression of Fl-BTx labeled WT $\alpha 7$-Venus receptors versus mutant $\alpha 7$ (Y442A)-Venus receptors was examined with a Nikon C1si spectral confocal microscope system using a Plan Apo VC $60 \times 1.4$ NA oil-immersion objective ( $0.13 \mathrm{~mm}$ working distance). A $\lambda$ stack of $\mathrm{X}-\mathrm{Y}$ images were collected simultaneously with one laser sweep onto an array of 32 photomultiplier tubes. Jurkat cells containing $\alpha 7$-Venus were imaged from 496.5 to $696.5 \mathrm{~nm}$ at $5 \mathrm{~nm}$ wavelength separation. Images were acquired at 512 pixels $\times 512$ pixels, at $25 \mu \mathrm{m} \times 25 \mu \mathrm{m}$ field of view and 12 bit intensity resolution. The pixel dwell time was set at $5.52 \mu$ s, and the pinhole was set to medium ( $60 \mu \mathrm{m}$ diameter). Fl-BTx was excited with a $638 \mathrm{~nm}$ laser line at $15 \%$ maximum intensity, and emission was measured at the emission peak channel $(665 \mathrm{~nm})$. Images were analyzed for mean signal intensity using ImageJ v1.43r software. Using JACoP (just another colocalization plugin) in ImageJ, we also calculated the Mander's coefficients, M1 and M2, which quantify the degree of overlap between $\alpha 7$-Venus and FI-Bgt (Manders et al., 1993). M1 measures the percentage of pixels in the red channel that overlaps with the signal in the green channel, whereas M2 measures the percentage of pixels in the green channel that overlaps with signal in the red channel. M1 and M2 coefficients were calculated for both control and ConA-treated Jurkat cells.

Statistical analysis. Values are reported as mean \pm SE. Significant differences ( $p<0.05$ ) between two groups of data were determined using a $t$ test for continuous data, meeting parametric assumptions of equal variances and normality. Otherwise, a Wilcoxon rank sum test was performed for nonparametric data. Comparison between three or more groups was analyzed using an ANOVA for parametric data followed by post hoc multiple pairwise analysis using a Tukey's HSD tests. For nonparametric data involving comparison of three or more groups of data, a Kruskal-Wallis rank sum test was performed followed by pairwise analyses using Wilcoxon rank sum tests. All statis- 
A
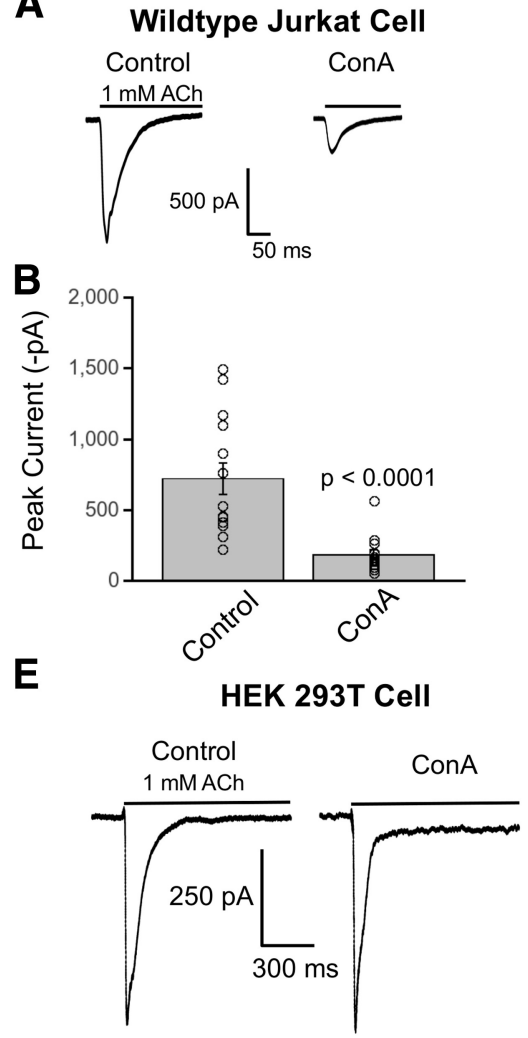
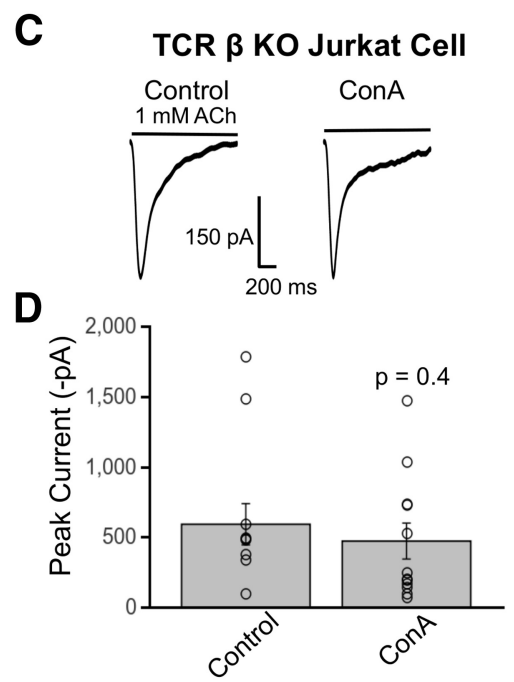

$\mathbf{F}$

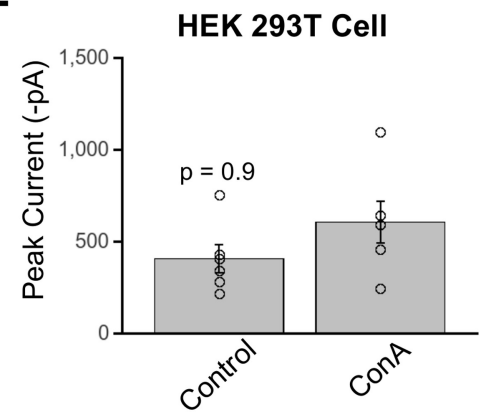

Figure 1. TCR activation decreases $\alpha 7 \mathrm{nAChR}$ responses in Jurkat cells. $\boldsymbol{A}-\boldsymbol{D}$, Whole-cell recordings showing representative traces of ACh (1 mM, $1 \mathrm{~s})$ induced $\alpha 7$ receptor currents in WT Jurkat cells $(\boldsymbol{A})$ and TCR $\beta$ KO Jurkat cells $(\boldsymbol{C})$. ConA incubation (75 $\mu \mathrm{g} / \mathrm{ml}, 30 \mathrm{~min}$ ) significantly decreased $\alpha 7 \mathrm{nAChR}$ currents in WT Jurkat cells $(n=14)$ compared with control treatment $(n=14)$ $(p<0.0001$, Wilcoxon rank sum test) $(\boldsymbol{A}, \boldsymbol{B})$, whereas ConA $(n=12)$ had no effect in TCR $\beta$ KO Jurkat cells compared with control treatment $(n=12)(p=0.4$, Wilcoxon rank sum test) $(\boldsymbol{C}, \boldsymbol{D}) . \boldsymbol{E}$, $\boldsymbol{F}$, Whole-cell recordings done in HEK293T cells transfected with $\alpha 7$ nicotinic receptor show that ConA incubation $(75 \mu \mathrm{g} / \mathrm{ml}$ for $30 \mathrm{~min})(n=6)$ has no effect on ACh-mediated current responses compared with control treatment $(n=6)(p=0.1, t$ test). Each circle superimposed on bar chart represent the average $\alpha 7$ nicotinic receptor response from each individual cell; bars represent mean \pm SE of responses averaged across all measured cells.

tical analyses were performed using the $\mathrm{R}$ statistical computing language (www.R-project.org).

\section{Results}

TCR activation decreases $\alpha 7 \mathrm{nAChR}$ responses in Jurkat cells Because the TCR complex is involved in downstream transmembrane signaling through src family tyrosine kinases, and $\alpha 7$ nicotinic receptors are negatively regulated by tyrosine kinases, we examined whether TCR activation could modulate the function of $\alpha 7$ receptors.

To test our hypothesis, we used Jurkat cells, which are a human clonal T lymphocyte cell line that natively expresses TCRs. We activated endogenously expressed TCRs with $75 \mu \mathrm{g} / \mathrm{ml}$ concanavilin A (ConA), a lectin and exogenous agonist of TCRs (Palacios, 1982). We found that Jurkat cells transiently transfected with $\alpha 7$ nicotinic receptors and incubated for $30 \mathrm{~min}$ with ConA resulted in a decrease in nicotinic current responses elicited by rapid application of ACh ( $1 \mathrm{~mm}$ for $1 \mathrm{~s})$ compared with Jurkat cells incubated with control solution (Fig. 1A). There was a significant decrease in the mean $\alpha 7$ peak current response in ConA-treated Jurkat cells $(185 \pm 34 \mathrm{pA}, n=14)$ compared with control $(720 \pm 113 \mathrm{pA}, n=14)(p<0.0001$, Wilcoxon rank sum test) (Fig. 1B).

To verify the role of TCR-mediated decrease in $\alpha 7$ nicotinic responses, we used a TCR $\beta$ subunit KO Jurkat cell line. In this cell line, the absence of the $\beta$ subunit renders the TCR receptor complex nonfunctional (Ohashi et al., 1985). Accordingly, the exogenous ligand ConA should not be able to activate the incomplete TCR complex. Indeed, we found no significant difference in the ACh-mediated $\alpha 7$ nicotinic currents between control $(590 \pm 147 \mathrm{pA}$, $n=12)$ and ConA $(470 \pm 128 \mathrm{pA}, n=12)$ treated TCR $\beta$ subunit KO Jurkat cells $(p=0.4$, Wilcoxon rank sum test) (Fig. 1D).

To further rule out the possibility that the effect of ConA was the result of a direct interaction with $\alpha 7$ nicotinic receptors, we used HEK293T cells, which are devoid of TCRs (Shaw et al., 2002). Similarly, we found no significant difference in $\alpha 7$ nicotinic currents in HEK293T cells treated with ConA (606 $\pm 114 \mathrm{pA}, n=6)$ compared with control treatment $(407 \pm 77$ pA, $n=6)(p=0.1, t$ test) (Fig. $1 F)$.

Together, these results demonstrate that the decrease in $\alpha 7$ nicotinic current responses in Jurkat cells is a TCR activation-dependent event.

\section{TCR activation decreases $\alpha 7$ nicotinic currents in layer 1 prefrontal cortical neurons}

We next asked whether the phenomenon of TCR regulation of $\alpha 7$ receptors we observed in Jurkat cells could be found in CNS neurons. TCR $\beta$ subunits are localized throughout all layers of the neocortex (Syken and Shatz, 2003), and $\alpha 7$ nicotinic receptors are present in layer 1 neocortical interneurons (Christophe et al., 2002) in addition to neurons in other cortical layers (Poorthuis et al., 2013). Thus, there is a high probability that TCRs and $\alpha 7$ nicotinic receptors are localized on the same neurons. We restricted our experiments to layer 1 of the medial frontal and prefrontal cortex, which is a simplified cortical layer essentially consisting almost entirely of GABAergic interneurons (Winer and Larue, 1989) and therefore is less heterogeneous than other layers, which contain pyramidal neurons and many subtypes of interneurons. To examine the functional interaction between TCRs and $\alpha 7$ receptors, we performed whole-cell patchclamp electrophysiology on layer 1 cortical neurons of the medial prefrontal cortex

In WT mouse brain slices incubated in ConA, using the $\alpha 7$ selective agonist PHA543613 (100 $\mu \mathrm{M}$ for $1 \mathrm{~s}$ ), we found that TCR activation significantly reduced $\alpha 7$-mediated currents $(36 \pm 6$ $\mathrm{pA}, n=10)$ compared with control-treated brain slices $(80 \pm 14$ pA, $n=12)(p=0.003$, Wilcoxon rank sum test) (Fig. $2 A)$. To isolate nicotinic responses, recordings were voltage-clamped at $-60 \mathrm{mV}$ and performed in the presence of TTX, CNQX, and atropine to inhibit action potential firing, glutamateric and muscarinic neurotransmission, respectively.

To confirm that the ConA-mediated reduction in peak $\alpha 7$ nicotinic currents in brain slices was a TCR-mediated event, we repeated the recordings in brain slices from TCR $\beta$ subunit KO mice (TCR $\beta \mathrm{KO}$ ). We found no significant difference in $\alpha 7$ 
nAChR peak current responses recorded from layer 1 prefrontal cortical interneurons between ConA $(156 \pm 50 \mathrm{pA}, n=10)$ and control treatments $(136 \pm 41 \mathrm{pA}, n=$ 10) $(p=0.7$, Wilcoxon rank sum test $)$ (Fig. 2B). These findings are consistent with our results in WT and TCR $\beta$ subunit KO Jurkat cells (Fig. 1). Interestingly, we also found a significant elevation in the baseline $\alpha 7$ nicotinic responses from layer 1 cortical neurons in brain slices from TCR $\beta$ KO mice $(136 \pm 41 \mathrm{pA}, n=12)$ compared with WT mice $(80 \pm 14 \mathrm{pA}$, $n=12)(p=0.0004$, Kruskal-Wallis rank sum test) ( $p=0.02$, Wilcoxon rank sum test post hoc analysis) (Fig. 2C). This result confirmed that TCRs, even in the absence of the exogenous compound ConA, had a basal activity that was sufficient to reduce $\alpha 7$ nicotinic currents in WT mice.

These data show that TCRs, which have traditionally been known to play an important role in adaptive immunity, also have a neuronal function in the CNS, which involves the negative regulation of function of $\alpha 7$ nicotinic receptors.

\section{TCR activation inhibits $\alpha 7$ nicotinic} currents via src family tyrosine kinases The earliest signaling events downstream of TCR stimulation are the activation of protein tyrosine kinases and the subsequent tyrosine phosphorylation of multiple intracellular proteins (Zhang et al., 1998). One of the earliest activated kinases upon TCR activation are the src family tyrosine kinases (Parsons and Parsons, 2004). Previous work done by Charpantier et al. (2005) and Cho et al. (2005) has shown that $\alpha 7$ nicotinic receptors are prone to modulation by tyrosine kinases. Therefore, we asked whether two src family kinases involved in TCR signaling, fyn and lck, play a role in the modulation of $\alpha 7$ nicotinic responses after TCR activation.

To investigate TCR regulation of $\alpha 7$ nicotinic receptors involves tyrosine kinase action, we compared $\alpha 7$ peak current responses to ConA in the presence and absence of the broadspectrum tyrosine kinase inhibitor genistein. Jurkat cells were transfected with $\alpha 7 \mathrm{nAChRs}$, and whole-cell electrophysiology was performed to compare the peak current responses between four different treatment groups: (1) control treatment, (2) ConA treatment $(75 \mu \mathrm{g} / \mathrm{ml}, 30 \mathrm{~min})$, (3) genistein preincubation (10 $\mu \mathrm{M}, 20 \mathrm{~min})$ followed by ConA $(75 \mu \mathrm{g} / \mathrm{ml}, 30 \mathrm{~min})$, and (4) genistein treated cells (10 $\mu \mathrm{M}, 20 \mathrm{~min})$ (Fig. 3A). When we inhibited tyrosine kinases with genistein alone, $\alpha 7$ nicotinic currents increased significantly $(2128 \pm 335 \mathrm{pA}, n=14)$ compared with control $(882 \pm 149 \mathrm{pA}, n=20)(p=0.0005$, Wilcoxon rank sum test post hoc analysis) (Fig. $3 B$ ). Genistein when preincubated for 20 min before ConA stimulation significantly decreased the AChmediated responses $(902 \pm 175 \mathrm{pA}, n=15)$ relative to genistein alone $(2128 \pm 335 \mathrm{pA}, n=14)(p=0.0009$, Wilcoxon rank sum test). However, with genistein plus ConA stimulation $\alpha 7$ nicotinic responses (902 $\pm 175 \mathrm{pA}, n=15)$ were not significantly different from $\alpha 7$ responses for control treatment ( $882 \pm 149 \mathrm{pA}$, $n=20)(p=0.8$, Wilcoxon rank sum test post hoc analysis).
B

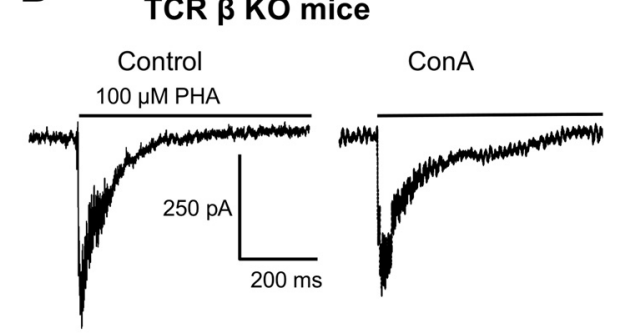

C

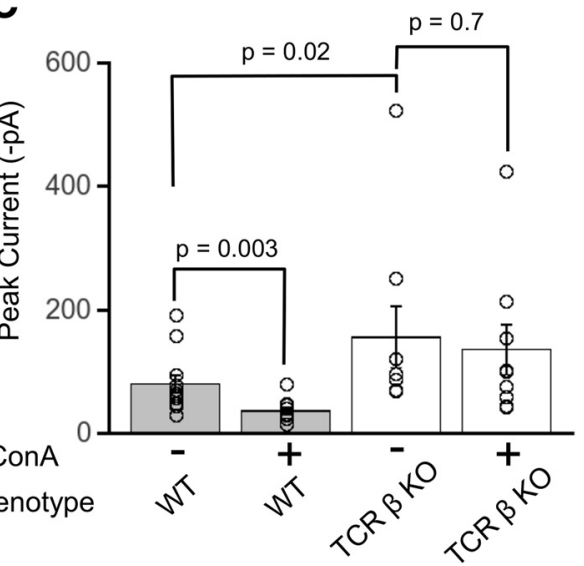

Figure 2. Activating TCRs decrease $\alpha 7$ nicotinic currents in layer 1 prefrontal cortical interneurons. A, C, Whole-cell recorded $\alpha 7$ nic current traces elicited by the $\alpha 7$ specific agonist PHA543613 (PHA, $100 \mu \mathrm{m}$ for $1 \mathrm{~s}$ ) showed a significantly diminished $\alpha 7$ treatment $(n=12)$ ( $p=0.003$, Wilcoxon rank sum test). Recordings were performed in the presence of TTX ( $200 \mathrm{~nm}$ ) and CNQX KO mice treated with ConA $(n=10)$ compared with control treatment $(n=10)(p=0.7$, Wilcoxon rank sum test). $C$, There was a significant increase in the mean baseline $\alpha 7$ nicotinic current amplitudes from neurons of TCR $\beta$ subunit null mice compared with $\alpha 7$ nicotinic currents from neurons of WT mice ( $p=0.02$, Wilcoxon rank sum test).

ConA alone $(398 \pm 62 \mathrm{pA}, n=14)$ had significantly attenuated $\alpha 7$ responses ( $p<0.0001$, Kruskal-Wallis rank sum test) ( $p=$ 0.02 , Wilcoxon rank sum test post hoc analysis) relative to control treatment $(882 \pm 149 \mathrm{pA}, n=20)$. These results are consistent with previously published work showing genistein-mediated potentiation of $\alpha 7$ nicotinic receptor currents (Charpantier et al., 2005; Cho et al., 2005).

Because the lck and fyn kinases are the primary kinases activated upon TCR stimulation (Parsons and Parsons, 2004), we next asked whether these tyrosine kinases regulate the activity of $\alpha 7$ nicotinic receptors. To examine the role of fyn kinase signaling in TCR modulation of $\alpha 7$ receptors, we cotransfected Jurkat cells with $\alpha 7 \mathrm{nAChRs}$ and either the gain of function (FKA) or the loss of function (FKD) Fyn kinase expression vector. Whole-cell recordings were then performed to monitor ACh-induced $\alpha 7$ nicotinic currents (Fig. 3C). We observed that $\alpha 7$ peak currents increased robustly and significantly in Jurkat cells cotransfected with FKD $(2286 \pm 241 \mathrm{pA}, n=34)$ compared with that of control $(970 \pm 163 \mathrm{pA}, n=39)(p<0.0001$, Kruskal-Wallis rank sum test) ( $p<0.0001$, Wilcoxon rank sum test post hoc analysis), whereas ConA treatment alone reduced $\alpha 7$ current responses $(501 \pm 87 \mathrm{pA}, n=22)$ relative to control $(p=0.02$, Wilcoxon rank sum test post hoc analysis) (Fig. 3D). However, in cells cotransfected with FKD, ConA stimulation in cells expressing FKD $(2706 \pm 631 \mathrm{pA}, n=7)$ did not lead to a significant change in the peak $\alpha 7$ current amplitude compared with control-treated FKD cotransfected cells $(2286 \pm 241 \mathrm{pA}, n=$ 34) ( $p=0.4$, Wilcoxon rank sum test post hoc analysis). The 
A

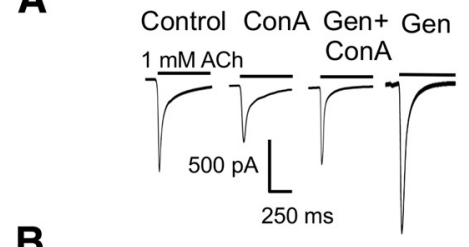

B

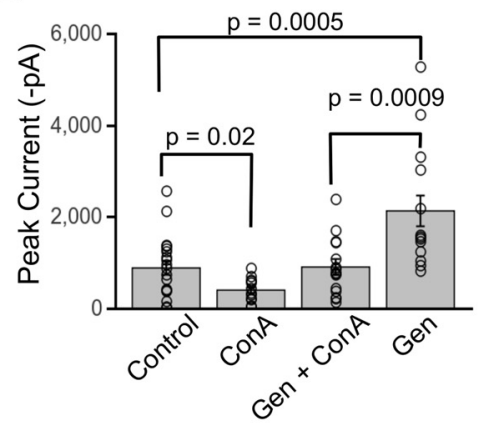

E

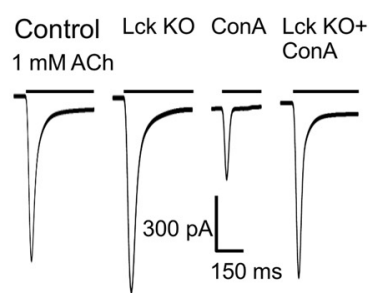

C

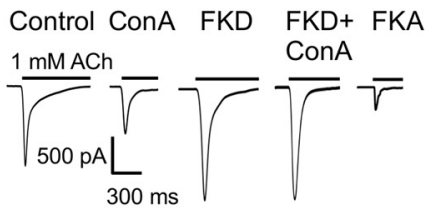

D

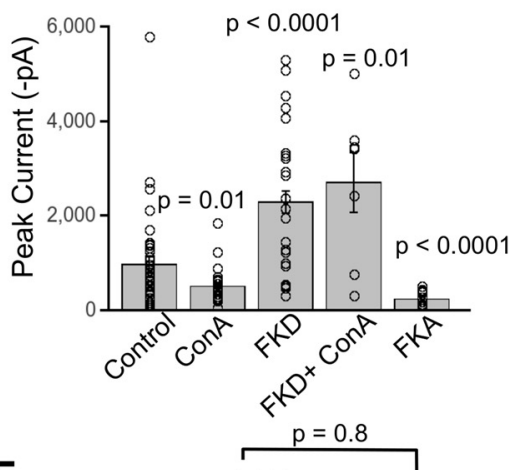

$F$

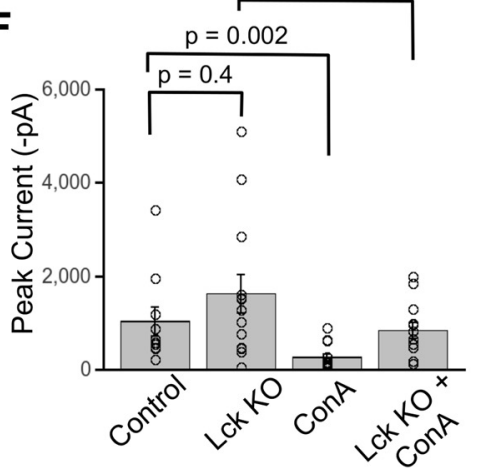

Figure 3. TCRs inhibit $\alpha 7$ nicotinic responses through activation of srcfamily tyrosine kinases. Whole-cell patch-clamp recordings from Jurkat cells transfected with $\alpha 7 \mathrm{nAChRs.} \boldsymbol{A}, \boldsymbol{B}, \mathrm{ACh}$ (1 mm for $1 \mathrm{~s}$ ) induced $\alpha 7 \mathrm{nAChR}$ currents in Jurkat cells show that TCRactivation by ConA (75 $\mu \mathrm{g} / \mathrm{ml}$ for $30 \mathrm{~min})(n=14)$ significantly decreased $\alpha 7 \mathrm{nAChRs}$ responses compared with control treatment $(n=20)(p=0.02$, Wilcoxon rank sum test). Preincubation with the tyrosine kinase inhibitor genistein (10 $\mu \mathrm{m}$ for $20 \mathrm{~min})(n=15)$ before ConA stimulation blocked the effect of ConA-mediated decrease in $\alpha 7$ nicotinic current. Genistein alone $(n=14)$ resulted in a significant enhancement of $\alpha 7$ nicotinic currents compared with control treatment $(n=20)(p=0.0005$, Wilcoxon rank sum test). The genistein alone treatment had significantly enhanced $\alpha 7$ nicotinic currents compared with ConA preincubated with genistein ( $p=0.0009$, Wilcoxon rank sum test). C, D, ConA stimulation ( $n=22)$ significantly reduced $\alpha 7$ nicotinic currents compared with control treatment $(n=39)(p=0.01$, Wilcoxon rank sum test). $\alpha 7$ receptor-mediated currents were significantly enhanced in cells cotransfected with a kinase dead form of fyn kinase (FKD) $(n=34)$ compared with control cells without FKD $(n=39)(p<0.0001$, Wilcoxon rank sum test), whereas cells cotransfected with FKD and treated with ConA $(n=7)$ still had augmented $\alpha 7$ currents compared with control ( $p=0.01$, Wilcoxon rank sum test). Cells cotransfected with a constitutively active fyn kinase (FKA) $(n=16)$ expressed significantly reduced $\alpha 7$ nicotinic responses compared with control cells ( $p<0.0001$, Wilcoxon rank sum test). $\boldsymbol{E}, \boldsymbol{F}, \alpha 7 \mathrm{nAChR}$ current traces from WT Jurkat cells and Ick K0 Jurkat cells. A significant decrease in $\alpha 7 \mathrm{nAChR}$ currents was observed between control-treated $(n=10)$ and ConA-treated $(n=13)$ WT Jurkat cells $(p=0.002$, Wilcoxon rank sum test). However, there was no significant difference in $\alpha 7 \mathrm{nAChR}$ currents between control-treated $(n=13)$ and ConA-treated ( $n=12)(p=0.8$, Wilcoxon rank sum test). These results suggest that both fyn and Ick contribute to TCR-mediated decrease in $\alpha 7 \mathrm{nAChR}$ currents.

abolition in TCR-mediated $\alpha 7$ current inhibition implicates the active role of fyn kinase in negatively modulating $\alpha 7$ nicotinic responses after TCR activation (Fig. 3C,D). When we cotransfected Jurkat cells with FKA and control treatment, it led to a significant decrease in the ACh-mediated $\alpha 7$ nicotinic responses $(235 \pm 39 \mathrm{pA}, n=16)$ compared with control treatment alone $(p<0.0001$, Wilcoxon rank sum test post hoc analysis) (Fig. $3 C, D$ ). The reciprocal effect of FKA and FKD suggests that fyn kinase modulates $\alpha 7$ nicotinic receptor regulation and that fyn kinase is one key downstream effector after TCR activation.

Because lck kinase also plays a critical role in mediating phosphorylation of ITAM residues and downstream TCR-mediated signaling (Weiss et al., 1992), we tested the possibility for the involvement of lck kinase in TCR-mediated $\alpha 7$ nicotinic receptor regulation. We used Jurkat cells devoid of lck kinase (lck KO). There were four experimental groups of cells transfected with $\alpha 7$ nAChRs: (1) WT Jurkat cells control treatment, (2) WT Jurkat cells ConA-treated, (3) lck KO Jurkat cells control treatment, and (4) lck KO Jurkat cells ConA-treated. Whole-cell recorded ACh evoked $\alpha 7$ nicotinic receptor responses showed significant reduction in WT Jurkat cells upon ConA stimulation $(261 \pm 76 \mathrm{pA}, n=13)$ compared with control $(1036 \pm 308 \mathrm{pA}, n=10)(p<$ 0.001 , Kruskal-Wallis rank sum test) $(p=$ 0.002 , Wilcoxon rank sum test post hoc analysis), consistent with previous data (Figs. 1 and 2). However, we observed no significant difference in $\alpha 7$ nicotinic currents between lck $\mathrm{KO}$ controls (1628 \pm $420 \mathrm{pA}, n=13)$ and ConA-treated lck KO cells $(842 \pm 179 \mathrm{pA}, n=12)(p=0.2$, Wilcoxon rank sum test post hoc analysis) (Fig. $3 F$ ). Furthermore, neither lck KO control-treated cells $(1628 \pm 420 \mathrm{pA}, n=$ 13) ( $p=0.4$, Wilcoxon rank sum test post hoc analysis) nor lck KO ConA-treated cells (842 $\pm 179 \mathrm{pA}, n=12)$ differed significantly ( $p=0.8$, Wilcoxon rank sum test post hoc analysis) in $\alpha 7$ nicotinic currents compared with control-treated WT Jurkat cells (1036 $\pm 308 \mathrm{pA}, n=10)$.

Together, these data strongly suggest that both lck and fyn kinases are required for TCR-mediated negative regulation of $\alpha 7$ nicotinic receptor function. Furthermore, these data suggest that fyn and lck are lined up in series and are not in parallel in the same TCR signaling pathway, either TCR-lck-fyn- $\alpha 7$ or TCR-fyn-lck- $\alpha 7$. Therefore, fyn and lck are each not redundant in function. However, there is one potentially paradoxical result in Figure $3 B$. Although ConA with genistein preincubation abolished the ConA-mediated decrease in $\alpha 7$ current and was not significantly different from control, ConA preincubated with genistein was still effective in decreasing the $\alpha 7$ current relative to genistein alone. This suggests that ConA was still effective in activating fyn and lck even when genistein preincubation, a general tyrosine kinase inhibitor, should inhibit these enzymes. The reason could be explained by the fact that genistein reversibly binds to src family of tyrosine kinases (Cho et al., 2005). Furthermore, unlike genistein, which must diffuse to its target and can also diffuse away, TCRs are structurally closely associated with fyn and lck kinases. Fyn coimmunoprecipitates with the TCR complex (Samelson et al., 1990), whereas lck physically interacts with the TCR coreceptor CD4 (Shaw et al., 1989). This may explain why TCR activation with ConA still attenuated $\alpha 7$ responses even with preincubation with 
genistein because the TCR has tighter association to fyn and lck than genistein.

Tyrosine 442 in the M3-M4 cytoplasmic loop of $\alpha 7$ nicotinic receptor is targeted by TCR activation

One mode by which TCR activation and fyn/lck kinases could affect $\alpha 7 \mathrm{nAChRs}$ is via receptor tyrosine phosphorylation. To test this, we monitored total tyrosine phosphorylation of $\alpha 7$ by immunoprecipitation and Western blots. Whole-cell extracts from Jurkat cells expressing $\alpha 7$-Venus-HA nictonic receptors, which have both a Venus fluorescent protein and an HA epitope tag, were generated (Dau et al., 2013), and $\alpha 7$ receptors were captured with anti-HA epitope antibody coated beads. Total $\alpha 7$ and tyrosine-phosphorylated $\alpha 7$ levels were monitored by Western blots using anti-HA and anti-4G10 antibodies, respectively (Fig. $4 A)$. Activation of TCRs with ConA (30 min) showed immunoprecipitated $\alpha 7$ nAChRs with higher tyrosine phosphorylation signal compared with that of the control-treated cells (Fig. 4A,B). Similarly, $\alpha 7$ nAChRs in cells cotransfected with constitutively active fyn kinase showed greater tyrosine phosphorylation than control cells (Fig. 4A). We calculated a tyrosine phosphorylation index by dividing the $\alpha 7$ tyrosine phosphorylation signal by the total $\alpha 7$ nicotinic receptor expression and found that there was a significant increase in tyrosine phosphorylation of $\alpha 7 \mathrm{nAChRs}$ in ConA-treated cells compared with control treatment (Fig. $4 B)(p=0.02$, Wilcoxon rank sum test). The bands analyzed were specific for $\alpha 7 \mathrm{nAChRs}$ as control immunoprecipitations with IgG-coated Sepharose beads were devoid of signal with either anti-HA or anti-phosphotyrosine antibodies (Fig. 4A). Thus, both TCR activation and fyn can potentiate tyrosine phosphorylation of $\alpha 7 \mathrm{nAChRs}$.

Using Prosite analysis of the amino acid sequence of the M3-M4 cytoplasmic loop of the $\alpha 7$ nicotinic receptor, we identified a putative tyrosine phosphorylation site at Tyr 442 of the receptor (EEVRYIANR). There are two other tyrosines (Y317 and Y386) in the $\alpha 7$ M3-M4 loop (IVLRYHHHD and GNLLYIGFR, respectively), which were not recognized as consensus sites for tyrosine kinase phosphorylation by Prosite. Furthermore, Y442 is conserved over all 11 mouse neuronal nicotinic receptor subunits, whereas neither Y317 nor Y386 is conserved in any other neuronal nicotinic receptor subunit. Thus, we focused our attention to investigate whether the effects of TCR activation and fyn tyrosine kinase were directed against the consensus tyrosine phosphorylation site at Y442 of the $\alpha 7$ nicotinic receptor.

To study the role of phosphorylation of $\alpha 7$ Tyr 442 on TCR regulation of $\alpha 7$ nicotinic receptor function, we mutated $\alpha 7$ Tyr 442 into alanine (Y442A). Whole-cell recordings were performed on stimulated Jurkat cells.
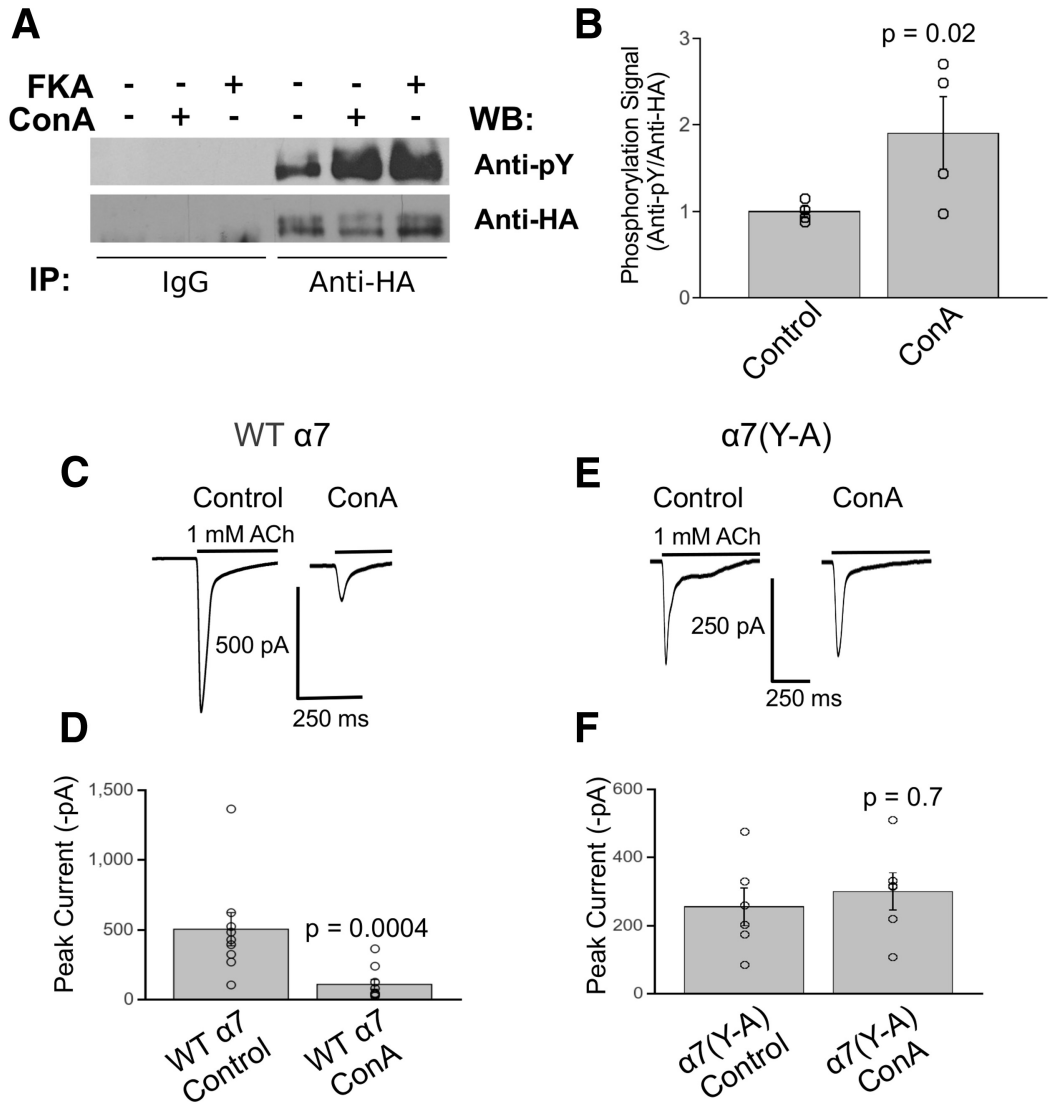

Figure 4. TCRactivation phosphorylates tyrosine 442 of $\alpha 7$ nicotinic receptors to decrease $A C$ ChR function. $A$, An immunoprecipitation and Western blot experiment demonstrates that TCR activation results in an increase in tyrosine phosphorylation of $\alpha 7$-Venus nAChRs, which also include an HA epitope tag. Anti-HA antibody-coated Sepharose beads are used to immunoprecipitate $\alpha 7$-Venus nAChRs and parallel blot with anti-HA antibody to determine total $\alpha 7$-Venus nAChRs. The first three lanes are negative controls of Jurkat cell samples expessing $\alpha 7$-Venus nAChRs and immunoprecipitated using IgG antibody. The next three lanes are samples immunoprecipitated with 政 pos signal is normalized to the anti-HA signal shows that ConA treatment $(n=4)$ significantly enhanced tyrosine nicotinic current traces elicited with $1 \mathrm{~mm} \mathrm{ACh}$ (1 s) and recorded from transfected Jurkat cells decreases in peak current amplitude after TCR activation with $30 \mathrm{~min}$ of $\operatorname{ConA}(75 \mu \mathrm{g} / \mathrm{ml})$ incubation. $\boldsymbol{D}$, Averaged data show a significant reduction in the mean current response between control $(n=10)$ and ConA $(n=9)(p=0.0004$, Wilcoxon rank sum test) treated Jurkat cells. $E$, In Jurkat cells transfected with the mutant $\alpha 7(\mathrm{Y}-\mathrm{A})$ nicotinic receptors, in which Y442 in the M3-M4 cytoplasmic loop, was mutated to alanine, no difference was ence ( $p=0.7$, Student's $t$ test) in ACh-mediated mutant $\alpha 7$ (Y442A) nAChRs responses between control $(n=6)$ and ConA $(n=6)$

WT Jurkat cells expressing mutant $\alpha 7$ nictonic receptors (Fig. $4 E, F)$. TCR activation with ConA stimulation for $30 \mathrm{~min}(300 \pm 54$ $\mathrm{pA}, n=6)$ resulted in no significant difference in the ACh-evoked $\alpha 7$ nicotinic current responses compared with control treatment $(255 \pm 56 \mathrm{pA}, n=6)(p=0.7, t$ test) (Fig. $4 E, F)$. However, TCR activation with ConA in the Jurkat cells expressing WT $\alpha 7$ nictonic receptors showed a significant decrease in peak response $(107 \pm 35$ $\mathrm{pA}, n=10)$ compared with that of control treatment $(502 \pm 119 \mathrm{pA}$, $n=9)(p=0.0004$, Wilcoxon rank sum test) (Fig. $4 C, D)$. These data strongly suggest that fyn/lck kinases modulate $\alpha 7$ nicotinic receptor function by directly targeting Y442 of $\alpha 7$ nAChRs.

\section{TCR activation decreases the number of surface $\alpha 7$ nicotinic receptors}

There is conflicting evidence regarding whether tyrosine kinases affect trafficking of $\alpha 7$ nicotinic receptors (Charpantier et al., 

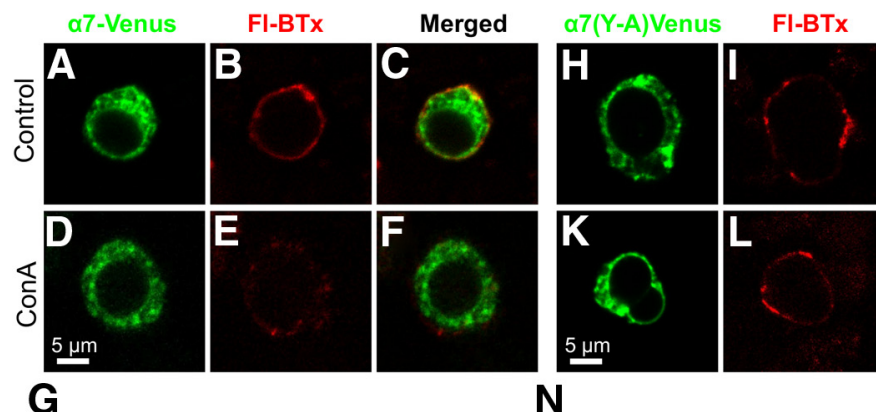

G
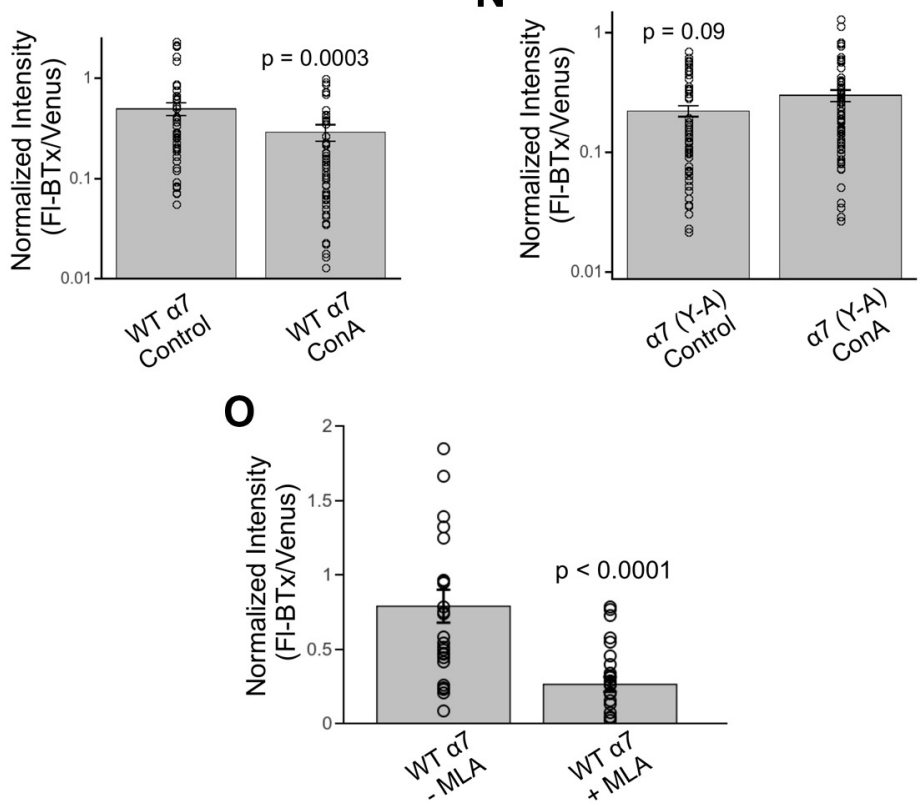

Figure 5. TCR activation decreases the number of $\alpha 7$ nAChRs expressed at the cell surface. $\boldsymbol{A}-\boldsymbol{F}$, Confocal images of Jurkat cells transfected with $\alpha 7$-Venus. Surface labeling of $\alpha 7$-Venus is performed with Alexa Fluor 647-conjugated $\alpha$-BTX (FI-BTx) under nonpermeabilizing conditions. ConA (75 $\mu \mathrm{g} / \mathrm{ml}$ for $30 \mathrm{~min}$ ) stimulation $(n=58)$ resulted in a significant decrease in the amount of surface $\alpha 7$-Venus receptors as determined with Fl-BTx labeling compared with control treatment $(n=58)(p=0.0003$, Wilcoxon rank sum test) (G). $\boldsymbol{H}-\mathbf{M}$, Confocal images of Jurkat cells transfected with a mutant $\alpha 7$-Venus in which the putative tyrosine phophorylated site (Y442) was mutated to alanine ( $\alpha 7(\mathrm{Y}-\mathrm{A})$ Venus). $\boldsymbol{N}$, Upon incubation with ConA $(75 \mu \mathrm{g} / \mathrm{ml}$ for $30 \mathrm{~min})(n=63)$, there was no significant change in Fl-BTx bound surface $\alpha 7$-Venus nAChRs compared with control treatment $(n=58)(p=0.09$, Wilcoxon rank sum test). Both bar charts are displayed in logarithmic scale and represent the mean \pm SE with each circle showing the measure from each individual cell. 0, Control experiment demonstrating the specificity of FI-BTx. Preincubation with $10 \mathrm{nMMLA}(n=26)$ is able to compete with and significantly lower Fl-BTx labeling compared with control treatment $(n=26)(p<0.0001$, Wilcoxon rank sum test).

2005; Cho et al., 2005). Because we found that TCRs signal through fyn and lck kinases to decrease $\alpha 7$ receptor function, we examined whether the effect of TCR activation in Jurkat cells could be attributed to a decrease in the number of surface receptors. To test this, we imaged Alexa Fluor 647-conjugated $\alpha$-BTX (Fl-BTx) binding on the surface of Jurkat cells transfected with $\alpha 7$-Venus under nonpermeablized conditions and normalized the surface bound Fl-BTx to the total cellular fluorescence from $\alpha 7$-Venus. ConA incubation ( $75 \mu \mathrm{g} / \mathrm{ml}$ for $30 \mathrm{~min}$ ) significantly decreased the number of surface Fl-BTx bound $\alpha 7$ nAChRs $(0.29 \pm 0.05, n=58)$ compared with that of the control-treated cells $(0.50 \pm 0.07, n=58)(p=0.0003$, Wilcoxon rank sum test $)$ (Fig. 5). However, the total cellular $\alpha 7$-Venus intensity remained the same for both treated and untreated cells (data not shown), implicating no change in the total level of protein.

In Jurkat cells transfected with mutant $\alpha 7$-Venus in which the putative tyrosine phosphorylation site, Tyr 442, is mutated to alanine ( $\alpha 7$ (Y-A)Venus), ConA activation of TCRs did not show any significant change in surface Fl-BTx bound $\alpha 7 \mathrm{nAChRs}$ $(0.30 \pm 0.03, n=63)$ compared with control treatment $(0.22 \pm$

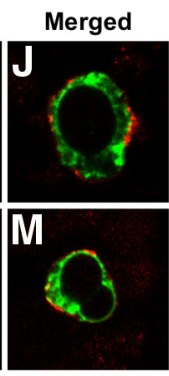

$0.02, n=58)(p=0.09$, Wilcoxon signed rank test) (Fig. $5 \mathrm{H}-\mathrm{N})$. We demonstrated the specificity of Fl-BTx labeling of $\alpha 7$ Venus receptors because preincubation of WT $\alpha 7$-Venus transfected Jurkat cells with 10 nM MLA $(0.26 \pm 0.05, n=26)$ was successful in competing for binding sites and significantly lowered $(p<0.0001$, Wilcoxon rank sum test) Fl-BTx signal compared with cells without MLA $(0.79 \pm 0.11, n=26)$ (Fig. 5O).

Furthermore, we analyzed the specificity of Fl-BTx labeling of $\alpha 7$-Venus receptors by performing quantitative analysis of colocalization via calculation of the Mander's coefficients, M1 and M2, the proportion of colocalized $\alpha 7$-Venus pixels to Fl-BTx pixels and vice versa, respectively. We compared these Mander's coefficients with those calculated when the Fl-BTx was rotated $90^{\circ}$ counterclockwise relative to the $\alpha 7$-Venus image, which should have less colocalization. We found that the Mander's coefficient of Fl-BTx colocalized to $\alpha 7$-Venus for both control $(0.44 \pm 0.03)$ and ConA $(0.44 \pm 0.03)$ treatment was significantly greater $(p=0.002$, and $p=0.0005$, Wilcoxon rank sum tests, respectively) than colocalization in the $90^{\circ}$ rotated images for control $(0.30 \pm 0.03)$ and ConA treatments $(0.28 \pm 0.02)$.

Thus, these measurements of Mander's colocalization coefficients validated the specificity of Fl-BTx labeling of $\alpha 7$ receptors and confirmed that TCR activation decreases the surface expression of $\alpha 7 \mathrm{nAChRs}$ without changing the amount of total cellular receptors through phosphorylation of Tyr 442.

\section{TCR activation decreases single- channel conductance of $\alpha 7$ nicotinic receptors}

A second potential mechanism for the inhibition of nicotinic current after TCR activation is a decrease in intrinsic channel function. Because Y442 is located in the amphipathic helix of $\alpha 7$, which lines the ion permeation pathway, the addition of a phosphate group here could hinder ion conductance because of added steric hindrance. Hence, we used ionic current fluctuation analysis of whole-cell recorded nicotinic currents in brain slices to calculate single-channel conductance. Ionic current fluctuation analysis is a reliable tool to estimate single-channel conductance of ion channels (Sigworth, 1980, 1981; Gill et al., 1995). Using this method, we aimed to determine whether a decrease in single-channel conductance of $\alpha 7$ nicotinic receptors contributed to the mechanism of TCR-mediated decrease in $\alpha 7$ whole-cell current responses. Examples of whole-cell recorded $\alpha 7$ nicotinic currents elicited with PHA543613 and the corresponding AC-filtered $\alpha 7$ nicotinic current (showing current fluctuation) are shown for each experimental condition (Fig. 6). Current fluctuations are maximal during the peak of the nicotinic current response and represent maximal number of channel openings. PHA543613 is applied repeatedly, and the variance of the current fluctuations of each trace is plotted against the mean current of 
the whole-cell current at each time point. The slope of the relationship gives the unitary current and when divided by the driving force $\left(\mathrm{V}_{\mathrm{h}}-\mathrm{E}_{\mathrm{rev}}\right)$ equals the singlechannel conductance $(\gamma)$.

The $\alpha 7$ receptor-mediated inward currents recorded from layer 1 prefrontal cortical interneurons of control-treated brain slices from WT mice $(118 \pm 34 \mathrm{pS}$, $n=12$ ) were accompanied by a significantly greater calculated single-channel conductance than those of ConA-treated WT brain slices $(30 \pm 12 \mathrm{pS}, n=8)(p=$ 0.02 , Wilcoxon rank sum test) (Fig. $6 A-$ $C)$. Exemplary graphs of current variance versus current mean were plotted and shown for $\alpha 7$ nicotinic receptor singlechannel conductances showing $61 \mathrm{pS}$ and $22 \mathrm{pS}$, respectively, for control and ConA incubated brain slices (Fig. 6A, B). To verify that TCR activation with ConA is responsible for the change in single-channel conductance, we performed fluctuation analysis of whole-cell recorded $\alpha 7$ nicotinic currents from TCR $\beta$ KO mice (Fig. $6 D-F)$. We calculated the single-channel conductance and observed no significant difference between brain slices treated with ConA $(130 \pm 68 \mathrm{pS}, n=4)$ compared with brain slices with control treatment $(118 \pm 23 \mathrm{pS} n=8)$ from TCR $\beta \mathrm{KO}$ mice $(p=0.5$, Wilcoxon rank sum test) (Fig. $6 F$ ). Plots of exemplary data of current fluctuation analyses are shown for control-treated and ConA-treated brain slices of TCR $\beta$ KO mice exhibiting singlechannel conductances of $101 \mathrm{pS}$ and 67 pS, respectively (Fig. 6D,E).

We further investigated the effects of TCR activation on modulating $\alpha 7$ channel gating kinetics recorded from layer 1 interneurons from WT brain slices. To examine the activation rate, we fitted the rise to peak of the $\alpha 7$ current with a single exponential and showed that there was no significant difference between the activation time constant for control treatment $(6.4 \pm 0.8$ $\mathrm{ms}, n=11)$ and ConA treatment $(5.6 \pm 0.7 \mathrm{~ms}, n=7)(p=0.8$, Wilcoxon rank sum test) (Fig. 7). The time course of the $\alpha 7$ decay kinetics during PHA543613 application was well fit by the sum of two exponentials. Similarly, ConA application did not result in any significant change in either the slow (control: $57.0 \pm 7.4 \mathrm{~ms}, n=11$ vs ConA: $62.1 \pm 16.4 \mathrm{~ms}, n=7$ ) or fast time constants (control: $15.0 \pm 2.5 \mathrm{~ms}, n=11$ vs ConA: $14.3 \pm 2.2 \mathrm{~ms}, n=7)(p=0.9$, Wilcoxon rank sum test, for both slow and fast time constants).

These data demonstrate that TCR activation inhibits $\alpha 7$ mediated whole-cell currents by decreasing their single-channel conductance but does not alter their gating kinetics.

Single-channel recordings verify that TCR activation reduces $\alpha 7$ nicotinic receptor single-channel conductance

To verify the whole-cell fluctuation analysis data that TCR activation decreases single-channel conductances of $\alpha 7$ nicotinic receptors, we
Wildtype mice

Control

A

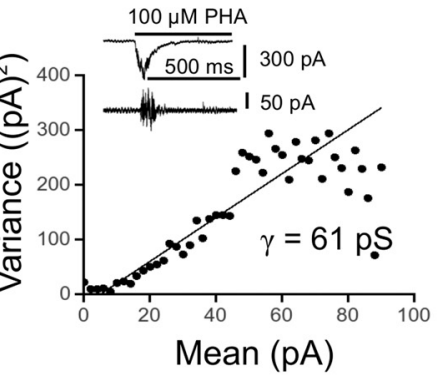

ConA

B

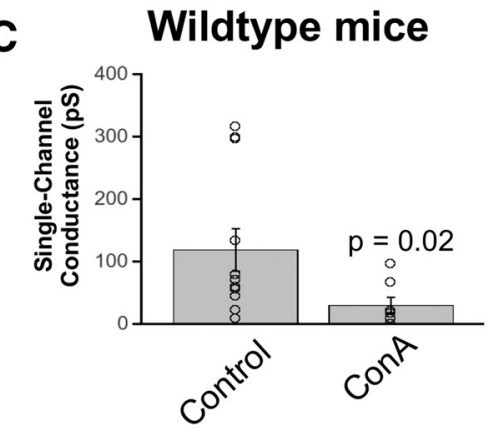

TCR $\beta$ KO mice

Control

D

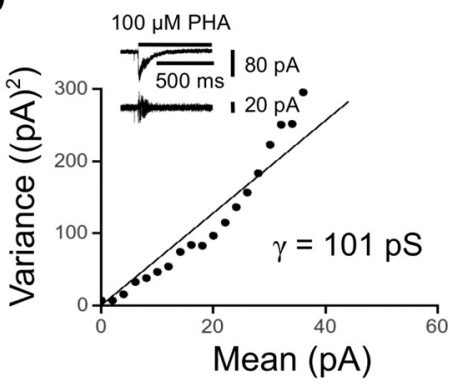

E

ConA

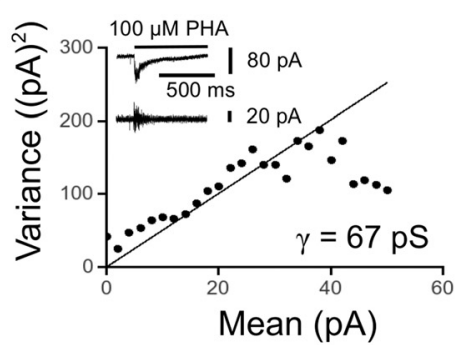

F TCR $\beta$ KO mice

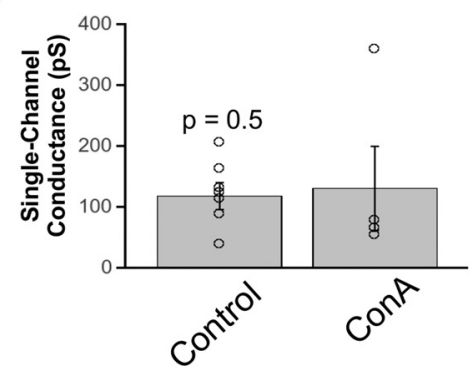

Figure 6. TCR activation attenuates single-channel conductance of $\alpha 7 \mathrm{nAChRs.} \boldsymbol{A}, \boldsymbol{B}$, Current variance-current relations for (B) versus mean current response. Inset, Whole-cell $\alpha 7$ nicotinic current waveforms and their respective AC-filtered wave政 mean current relations for $\alpha 7$ nicotinic whole-cell currents recorded for both control $(\boldsymbol{D})$ and ConA treatments $(\boldsymbol{E})$ from layer 1 interneurons from TCR $\beta$ KO mice. $\boldsymbol{F}$, There was no significant difference in the mean single-channel conductance for $\alpha 7$ receptors between control $(n=7)$ and ConA-treated slices $(n=5)$ of TCR $\beta$ K0 mice ( $p=0.5$, Wilcoxon rank sum test).

performed single-channel recordings in cell-attached configuration from WT Jurkat cells exposed to either control or ConA $(75 \mu \mathrm{g} / \mathrm{ml}$ for $30 \mathrm{~min}$ ) solutions. Single-channel $\alpha 7$ nicotinic receptormediated currents were activated by having ACh $(100 \mu \mathrm{M})$ in the patch pipette electrode solution. The extracellular solution was identical to the patch pipette recording solution minus ACh. The patch of membrane in cell-attached mode was voltage-clamped at a pipette potential of $60 \mathrm{mV}$. This would equal a transmembrane potential of $-60 \mathrm{mV}$ plus the resting membrane potential of the cell, which was on average $-48 \mathrm{mV}$. Thus, the estimated transmembrane potential was $-108 \mathrm{mV}$. When plotting histograms of the current amplitudes of the fitted open single-channel events, there was a significant reduction ( $p<0.0001$, Wilcoxon rank sum test) in $\alpha 7$ single-channel amplitudes of ConA-treated cells $(2.4 \pm 0.0 \mathrm{pA}, n=13902$ open channel events $>4$ cells) compared with control treatment $(6.0 \pm$ $0.1 \mathrm{pA}, n=1471$ open channel events $>4$ cells) (Fig. $8 A-D$ ). This 
A
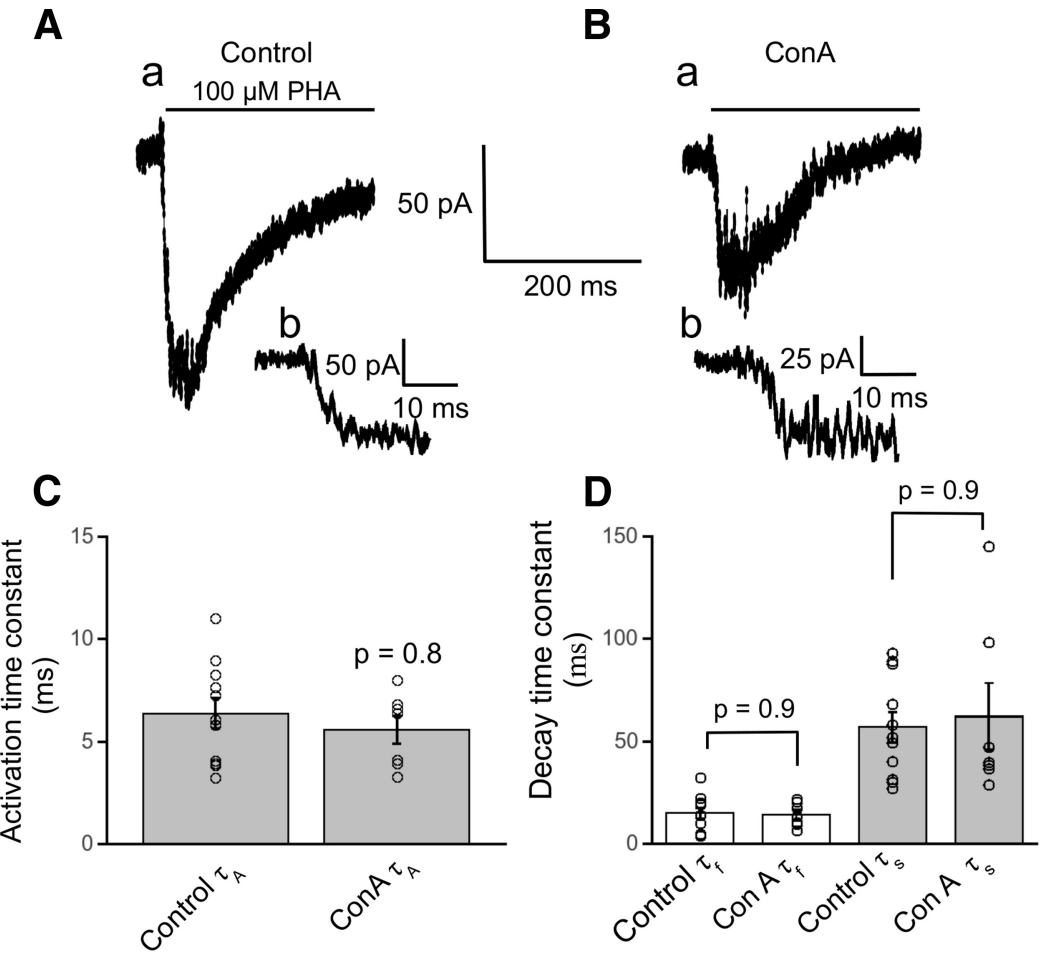

Figure 7. TCR activation does not alter gating kinetics of $\alpha 7 \mathrm{nAChRs.} A, \boldsymbol{B}$, Whole-cell recorded PHA-543613 $(100 \mu \mathrm{M}, 1 \mathrm{~s})$ activated $\alpha 7$ nicotinic current traces from control-treated $(\boldsymbol{A a})$ and $C$ onA-treated $(\boldsymbol{B a})$ layer 1 interneurons of medial prefrontal cortical brain slices. Insets, Higher time resolution comparable rates of activation rise times of $\alpha 7$ nicotinic currents for both control $(\boldsymbol{A b})$ and ConA treatments $(\boldsymbol{B} \boldsymbol{b})$. $\boldsymbol{C}$, There was no significant difference in the activation time constant between control $(n=11)$ and ConA $(n=7)$ treatments ( $p=0.8$, Wilcoxon rank sum test). $\boldsymbol{D}$, Furthermore, ConA treatment did not result in a significant change in either the fast (control: $15.0 \pm 2.5 \mathrm{~ms}, n=11$ vs ConA: $14.3 \pm 2.2 \mathrm{~ms}, n=7$ ) or the slow (control: $57.0 \pm 7.4 \mathrm{~ms}, n=$ 11 vs ConA: $62.1 \pm 16.4 \mathrm{~ms}, n=7$ ) decay time constants ( $p=0.9$, Wilcoxon rank sum test, for both fast and slow time constants).

corresponds to single-channel conductances of $22.0 \pm 0.1 \mathrm{pS}$ for ConA-treated cells and $55.5 \pm 0.6 \mathrm{pS}$ for control-treated cells. We also verified the conductance change by measuring the slope conductance of single-channel currents measured over various holding pipette potentials. Using this paradigm, we examined a controltreated cell with cell-attached single-channel currents having a higher slope conductance (41.4 pS) than a ConA-treated cell (14.6 pS) (data not shown).

To determine the effects of TCR activation on the gating kinetics of $\alpha 7$ nicotinic receptors, we plotted histograms of durations of single-channel open events and closed events for both control and ConA treatments (Fig. $8 E-H$ ) and then fitted the histograms to multiple exponential functions. Each histogram represents the combined data from four separate cell-attached patch-clamp recordings. We report the fitted time constants and the SEs of fit. For controltreated cells, the open channel duration histogram was fitted to a sum of two exponentials with time constants: $\tau 1=0.12 \pm 0.32 \mathrm{~ms}$ and $\tau 2=0.66 \pm 0.49 \mathrm{~ms}$. For ConA-treated cells, the open channel duration histogram was fitted with a sum of two exponentials with $\tau 1=0.07 \pm 0.10 \mathrm{~ms}$ and $\tau 2=0.42 \pm 0.21 \mathrm{~ms}$. Therefore, for the duration of the single-channel open events, there was no significant difference in the time constants between control ( $n=4$ patches) and ConA treatments ( $n=4$ patches) ( $p>0.25$, Wilcoxon rank sum test). Similarly, the durations of the closed single-channel events did not significantly differ between control ( $n=4$ patches) and ConA treatments ( $n=4$ patches) ( $p>0.15$, Wilcoxon rank sum test). Closed single-channel duration events for control-treated cells were fit with the sum of four exponentials with $\tau 1=0.20 \pm 0.12 \mathrm{~ms}, \tau 2=$ $1.95 \pm 0.13 \mathrm{~ms}, \tau 3=33.7 \pm 0.2 \mathrm{~ms}$, and $\tau 4=1311.8 \pm 0.2 \mathrm{~ms}$. For
ConA-treated cells, the closed singlechannel durations were well fit with the sum of five exponentials: $\tau 1=0.10 \pm 0.10 \mathrm{~ms}$, $\tau 2=0.47 \pm 0.13 \mathrm{~ms}, \tau 3=3.42 \pm 0.09 \mathrm{~ms}$, $\tau 4=29.1 \pm 0.1 \mathrm{~ms}$, and $\tau 5=227.0 \pm 0.1$ ms.

Thus, our single-channel data corroborate the whole-cell recorded current fluctuation analysis that TCR activation attenuates $\alpha 7$ mediated single-channel conductance while having little effect on gating kinetics.

\section{TCR activation decreases action potential firing frequency of layer 1 cortical neurons}

We examined the physiological consequence of decreasing $\alpha 7$ nicotinic receptor currents after TCR activation by measuring action potential firing rate of layer 1 cortical interneurons. Because most cortical neurons in brain slices lack the intrinsic ability to spontaneously fire action potentials resulting from severed afferent inputs, we performed current-clamp recordings in whole-cell configuration mode from layer 1 interneurons and applied depolarizing constant current steps $(0-200 \mathrm{pA}, 20$ pA steps for $500 \mathrm{~ms}$ ). To ascertain the excitability of the recorded neuron, we plotted input-output curves of current injection versus action potential frequency.

To test whether $\alpha 7$ nicotinic receptors contribute to the firing rate of layer 1 prefrontal cortical interneurons, we bathapplied 10 nM MLA ( $\alpha 7$ nAChR competitive antagonist) $(n=7)$ and noticed a significant decrease in the action potential firing frequency compared with baseline control $(n=7)(p<0.0001$, MLA factor, two-way ANOVA) (Fig. 9A-C). All the recorded neurons included in the analysis had stable resting membrane potentials that were more negative than $-60 \mathrm{mV}$ and overshooting action potentials. There was no significant difference in the mean resting membrane potential and $R_{\text {input }}$ between control and MLA-treated slices (data not shown). If an $\alpha 7$ antagonist decreased neuronal excitability, then a specific $\alpha 7$ agonist, PHA543613, should increase neuronal excitability. Indeed, when PHA543613 (100 $\mu \mathrm{M}$ for $575 \mathrm{~ms})$ was applied $75 \mathrm{~ms}$ preceding and during a $200 \mathrm{pA}(500 \mathrm{~ms})$ depolarization, there was a significant increase ( $p=0.03, n=7$, paired $t$ test) in action potential firing frequency $(30 \pm 2 \mathrm{~Hz})$ in the same neuron compared with when there was only $200 \mathrm{pA}$ depolarization but no costimulation with PHA543613 (27 $\pm 2 \mathrm{~Hz}$ ) (Fig. 9G,H).

Because TCR activation results in the inhibition of $\alpha 7$ nicotinic receptor currents, to examine the involvement of TCRs in modulating the firing rate of layer 1 interneurons, we compared whole-cell current-clamp recordings of control-treated brain slices from WT mice ( $n=7)$ with ConA-treated brain slices from WT mice $(n=9)$. We found a significant decrease in the mean firing frequency of ConA-treated WT brain slices $(18 \pm 4 \mathrm{~Hz})$ compared with control-treated WT brain slices $(26 \pm 3 \mathrm{~Hz})(p<$ 0.0001, treatment factor, two-way ANOVA) (Fig. $9 A, D, F)$.

If ConA-mediated activation of TCRs caused a decrease in neuronal firing rate due to decreased $\alpha 7$ nicotinic receptor currents, then we would predict an increase in firing rate in TCR $\beta$ 
subunit KO mice because baseline $\alpha 7$ nicotinic currents in TCR $\beta \mathrm{KO}$ mice have elevated $\alpha 7$ nicotinic currents in brain slices (Fig. 2C). A comparison of the mean action potential firing frequency showed a significant increase in neurons recorded from control-treated brain slices of TCR $\beta$ $\mathrm{KO}$ mice $(40 \pm 5 \mathrm{~Hz}, n=10)$ compared with neurons from control-treated brain slices of WT mice $(26 \pm 3 \mathrm{~Hz}, n=7)(p<$ 0.0001, genotype factor, two-way ANOVA) (Fig. $9 A, E, F$ ).

We performed current-clamp experiments in layer 1 interneurons from brain slices of $\alpha 7 \mathrm{nAChR}$ KO mice to determine whether TCR modulation of neuronal excitability was through $\alpha 7$ receptors. ConA incubation $(n=6)$ in $\alpha 7 \mathrm{nAChR}$ null slices showed similar levels of neuronal excitability as control treatment $(n=11)$ for much of the range of stimulation intensities ( $p=0.25$, ConA vs control treatment, two-way ANOVA) (Fig. 9I). Indeed, when averaging over all current stimulation intensities the ConAmediated decrease in frequency in neuronal firing from $\alpha 7 \mathrm{nAChR}$ null mice $(n=$ 6) was significantly less than the ConAmediated decrease in neuronal firing frequency in WT mice $(n=9)(p=0.005$, Wilcoxon rank sum test) (Fig. $9 J$ ). This supports that TCR activation is attenuating neuronal excitability through modulation of $\alpha 7 \mathrm{nAChRs}$.

This set of data shows that $\alpha 7$ nAChRs contribute to the excitability of layer 1 cortical neurons and that TCR-mediated inhibition of $\alpha 7$ receptor function contributed to reduced neuronal excitability. The source of ACh to activate $\alpha 7 \mathrm{nAChRs}$ in the cortex may be from cut cholinergic terminals from neurons originating from the nucleus basalis magnocellularis. There has even been a recent report showing local cholinergic interneurons in the cerebral cortex (von Engelhardt et al., 2007).

\section{Discussion}

This study shows, for the first time, that the immune protein, the TCR, can modulate nAChR function and neuronal activity in the brain. Activating TCRs decreases the function of $\alpha 7 \mathrm{nAChRs}$ in Jurkat cells and in layer 1 interneurons of the medial prefrontal cortex. The mechanism of TCRmediated dampening of $\alpha 7$ nicotinic currents was the result of downstream activation of src family tyrosine kinases, namely, fyn and lck kinases. TCRs' effect of attenuating $\alpha 7 \mathrm{nAChR}$ responses is mediated through Y442 of $\alpha 7$ because mutating Y442 to alanine in the $\alpha 7$ nAChR blocked TCRs' negative modulation. TCR activation leads to a decrease in the number of surface $\alpha 7$ nAChRs. TCR activation also decreases $\alpha 7$ single-channel conductance. Furthermore, TCRs and $\alpha 7$ nAChRs influence neuronal excitability. Inhibition of $\alpha 7$ receptors decreases the frequency of action potentials. Activation of TCRs also inhibited the neuronal firing
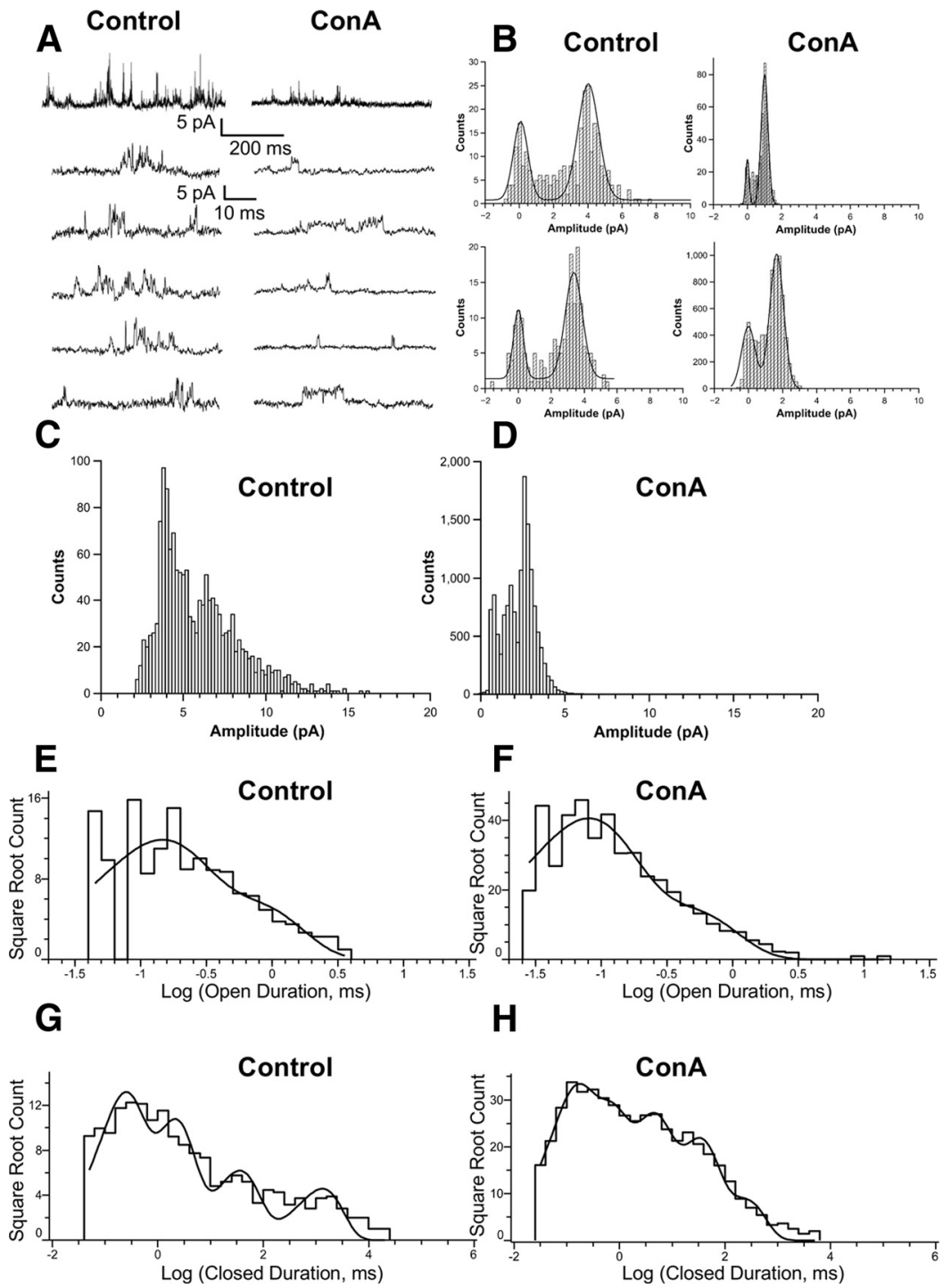

Figure 8. Single-channel recordings show that TCR activation decreases single-channel conductance of $\alpha 7 \mathrm{nAChRs.} \boldsymbol{A}$, Examples of Jurkat cell-attached single-channel traces for control and ConA treatment. The ConA-treated single-channel responses have smaller single-channel current amplitudes than control treatment. The patch electrode solution contained $100 \mu \mathrm{m}$ ACh. $\boldsymbol{B}$, Histosmaller single-channel amplitudes than control treatment. $\boldsymbol{C}, \boldsymbol{D}$, Histograms of single-channel amplitudes showing the combined data of all patches recorded for control $(n=4)$ and ConA $(n=4)$ treated Jurkat cells showing that ConA treatment caused a of open single-channel events are shown for clarity. $\boldsymbol{E}, \boldsymbol{F}$, Histograms of open duration of single-channel events compiled from all patches show no difference in distributions between control and ConA treatment. $\mathbf{G}, \boldsymbol{H}$, The histograms of closed duration of single-channel events show similar kinetics between ConA and control-treated cells.

frequency, whereas neurons from TCR $\beta$ KO mice exhibited enhanced firing rate of action potentials. Thus, the TCR-mediated regulatory mechanism of $\alpha 7 \mathrm{nAChR}$ function illustrates a novel role of TCRs in the CNS affecting ligand-gated ion channel function and neuronal excitability.

\section{TCRs modulate neural function and $\alpha 7 \mathrm{nAChR}$ activity}

To our knowledge, this is the first demonstration that TCRs in the CNS can modify neuronal activity and that one of the mechanisms is through modulation of $\alpha 7 \mathrm{nAChR}$ function. We have shown that TCRs can decrease $\alpha 7$ currents in prefrontal cortical interneurons (Fig. 2). Our data also show that there is endogenous activation of TCR-mediated decrease of $\alpha 7$ responses in the CNS because TCR $\beta$ subunit KO mice had significantly larger $\alpha 7$ 


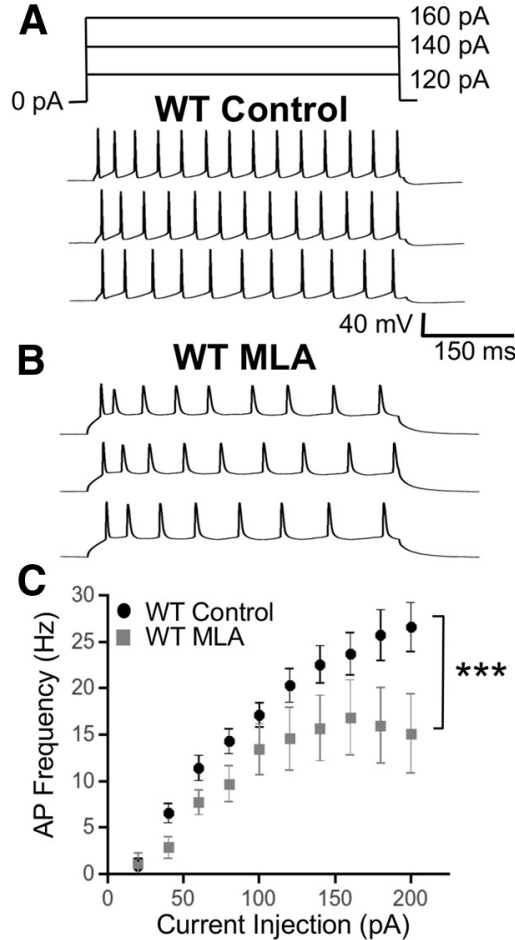

D

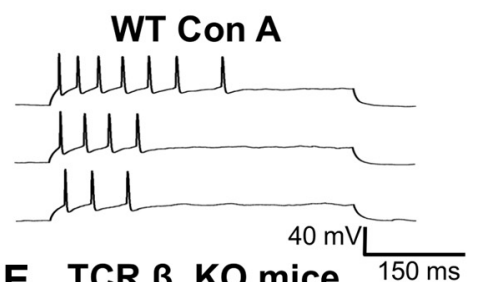

E TCR $\beta$ KO mice $150 \mathrm{~ms}$

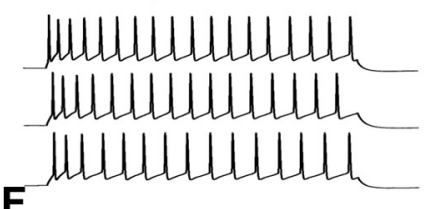

$\mathbf{F}$

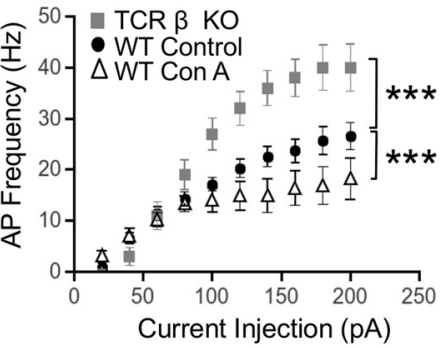

WT PHA

G
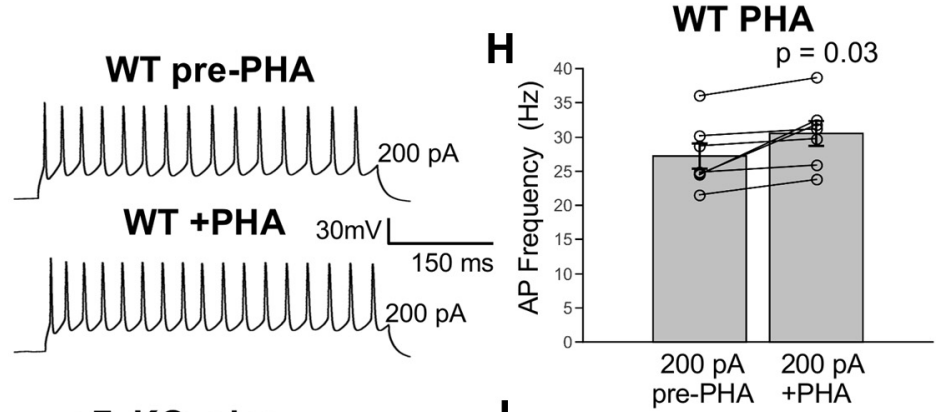

I

a7 KO mice

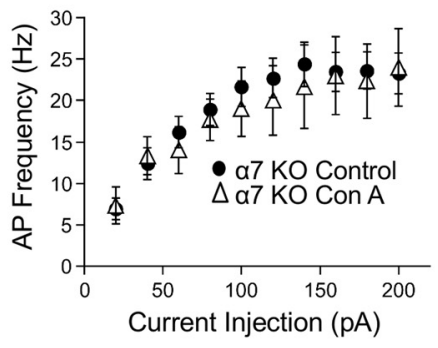

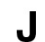

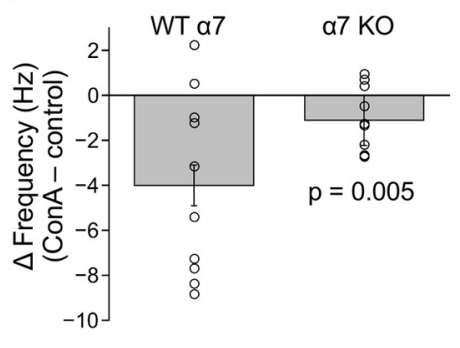

Figure 9. TCR activation modulates neuronal excitability of layer 1 cortical interneurons. $A, B$, Firing frequency of layer 1 cortical neurons is modulated by $\alpha 7$ nicotinic receptors as evidenced by the decrease in action potential firing in the presence of a specific $\alpha 7$ antagonist, MLA (10 nM) in brain slices from WT mice. Current-clamp recordings are shown for current steps (120, 140, and 160 $\mathrm{pA})$. C, The action potential firing rate of layer 1 interneurons in response to current steps $(0-200 \mathrm{pA})$ was significantly lower with MLA treatment $(n=7)$ compared with control treatment from WT mouse brain slices $(n=7){ }^{* * *} p<0.0001$, MLA factor, two-way ANOVA). $E, F$, A significant increase in the action potential firing rate was observed in layer 1 cortical neurons from control-treated TCR $\beta$ KO mice $(n=10)$ compared with control-treated WT mice $(n=7)\left({ }^{* * *} p<0.0001\right.$, genotype factor, two-way ANOVA) over current steps ranging between 0 and 200 pA. $A, D, F$, WT brain slices with ConA treatment $(n=9)$ resulted in a significant decrease in the action potential firing rate of layer 1 cortical interneurons compared with control-treated WT mouse brain slices $(n=7)\left({ }^{* * *} p<0.0001\right.$, two-way ANOVA) (current steps ranged between 0 and $\left.200 \mathrm{pA}\right) . \mathbf{G}, \boldsymbol{H}$, There was a significant increase ( $p=0.03, n=7$, paired $t$ test) in action potential frequency upon PHA543613 (PHA, $100 \mu \mathrm{m}$ ) coapplication with $200 \mathrm{pA}$ than with $200 \mathrm{pA}$ depolarizing stimulation alone from brain slice recordings obtained from WT mice. I, Current-clamp recordings from layer 1 interneurons from $\alpha 7 \mathrm{nAChR}$ KO mice show that ConA treatment $(n=6)$ displays similar neuronal excitability compared with control treatment $(n=11)(p=0.25$, ConA vs control treatment factor, two-way ANOVA). Each connected pair of circles represents the frequency before and after PHA application for one cell. $J$, In brain slices of WT mice, there was a significantly greater attenuation in action potential firing frequency with ConA treatment $(n=9)$ compared with ConA treatment of $\alpha 7 \mathrm{nAChR}$ K0 mice $(n=6)(p=0.005$, Wilcoxon rank sum test). J, Each circle represents the mean ConA-mediated decrease in firing frequency for one specific current stimulation. currents than WT mice (Fig. 2). We also observed that TCRs modulate neuronal excitability. TCR activation resulted in a significant decrease in current-evoked action potential firing, whereas in TCR $\beta$ subunit KO mice neurons had a significantly enhanced action potential firing (Fig. 9). The TCR is an octameric complex that includes the $\mathrm{CD} 3 \zeta$ subunit. $\mathrm{CD} 3 \zeta$ plays an important role in dendritic structure and development in cultured hippocampal and cortical neurons (Baudouin et al., 2008).

\section{TCRs decrease $\alpha 7$ nAChR function through phosphorylation of tyrosine $\mathbf{4 4 2}$}

Our Western blot and electrophysiology data support that TCRs have effect through phosphorylation of $\alpha 7$ receptors at tyrosine 442 (Fig. 4), which is the only putative tyrosine phosphorylation site within the cytoplasmic loop of $\alpha 7$ recognized by ProSite analysis. We show that both fyn and lck kinases are involved in TCR-mediated attenuation of $\alpha 7$ nicotinic responses because FKD or deletion of lck both prevented ConA from decreasing $\alpha 7$ activity (Fig. 3). Overexpressing FKD successfully competed with endogenously expressed Fyn kinase. Because genistein, a broad-spectrum inhibitor of tyrosine kinase, and FKD both augmented $\alpha 7$ currents (Fig. 3), our results are consistent with the results of Charpantier et al. (2005) and Cho et al. (2005). Furthermore, we were able to abolish the effect of ConA-stimulated TCR-mediated decrease in $\alpha 7$ responses by mutating tyrosine 442 to alanine. This is consistent with the results of Charpantier et al. (2005) who also mutated tyrosine 386 and tyrosine 442 to alanines but did not distinguish the effect of each tyrosine. We propose that tyrosine 442 is the key tyrosine that is phosphorylated and induces altered $\alpha 7 \mathrm{nAChR}$ function after TCR activation. However, our results are at odds with that of Cho et al. (2005), who mutated tyrosine 317,386 , or 442 to phenylalanine without any effect on genistein-mediated potentiation of $\alpha 7$. One potential caveat of site-directed mutagenesis is that mutating one amino acid into another may have more than the intended consequence. Mutating tyrosine to another amino acid may alter the structure of the protein because the functional properties of amino acid side groups and their degree of hydrophobicity play a role in stabilizing protein conformation (Yutani et al., 1987). In our study, as in those of Charpantier et al. (2005), the mutation 
was made to alanine, whereas Cho et al. (2005) mutated the residue to phenylalanine, which may explain the discrepancy.

\section{Mechanisms of TCR-mediated decrease of $\alpha 7$ currents}

Our exploration of the mechanisms of TCR-mediated decrease in nAChR function indicate two contributing parallel steps: (1) a decrease in surface $\alpha 7$ receptors; and (2) a decrease in singlechannel conductance. Our results showing a decrease in cell surface receptors upon TCR stimulation using Fl-BTx binding are consistent with the results of Cho et al. (2005), who showed that inhibition of tyrosine kinase with genistein enhanced surface $\alpha 7$ receptors, whereas Charpantier et al. (2005) showed no alterations in surface $\alpha 7$ receptors when inhibiting tyrosine kinase activity. This TCR-mediated decrease in surface receptors is mediated by phosphorylation of tyrosine 442 because mutation of this residue to alanine in $\alpha 7$ completely abolished TCRs' effect of decreasing surface $\alpha 7$ receptors (Fig. 5).

Interestingly, tyrosine 442 lies within the amphipathic helix. The amphipathic helix lines the cytoplasmic side portals of cys-loop receptors and forms part of the ion permeation pathway (Hales et al., 2006). We found that TCR activation decreases the single-channel conductance of $\alpha 7$ receptors (Figs. 6 and 8). This allows a unique property of reversible modification of single-channel function through post-translational modification, namely, tyrosine phosphorylation. This is consistent with the results of Charpantier et al. (2005), who proposed that tyrosine phosphorylation of $\alpha 7$, which decreased macroscopic currents, was the result of alterations in channel function. We further examined whether the gating kinetics of $\alpha 7$ were also affected by TCR activation. We analyzed the activation and desensitization kinetics and open and closed channel durations (Figs. 7 and 8) and determined that $\alpha 7$ gating kinetics were unaffected by TCR activation. Thus, only single-channel conductance is decreased by TCR activation.

\section{Physiological role of TCRs in the CNS}

Our study demonstrates that an immune protein receptor complex, the TCR, has a neuronal function in the CNS. TCRs play an important role in modulating postsynaptic cholinergic neurotransmission by dampening $\alpha 7$ nicotinic currents (Fig. 2). Although we used an exogenous compound ConA for stimulation of TCRs, we also have evidence that endogenous activation of TCRs already occurs in the CNS, which dampens $\alpha 7$ currents. This is shown by significantly augmented $\alpha 7 \mathrm{nAChR}$ currents from layer 1 interneurons of TCR $\beta$ KO mice compared with WT (Fig. 2). Furthermore, both TCR signaling and $\alpha 7$-mediated neurotransmission affect neuronal excitability because inhibition of $\alpha 7$ with MLA decreases action potential firing similar to TCR activation with ConA, whereas neurons from TCR $\beta$ KO mice had elevated firing frequency (Fig. 9).

TCR modulation of $\alpha 7$ receptors involves a unique form of cellular signaling in the CNS. Unlike the receptor tyrosine kinases, insulin receptor (Ahmadian et al., 2004; Cho et al., 2005) and TrkB receptor (Zhou et al., 2004; Fernandes et al., 2008) signaling, which involve the release and binding of insulin and brain-derived neurotrophic factors to their respective receptors, the TCR is an octameric receptor complex, which binds to an antigen presented by either MHCI or MHCII found on the surface of the antigenpresenting cell. MHCI molecules are widely distributed in the CNS (Huh et al., 2000) and reside on neurons and microglia (Tooyama et al., 1990; Neumann et al., 1997; Corriveau et al., 1998). We propose that TCR-mediated tyrosine kinase signaling is based on cell-cell contacts and therefore senses neighboring cells by binding to MHCI of adjacent neurons or microglia. Interestingly, microglia are in- volved in the pruning of synaptic spines, as evidenced by synaptic material engulfed by microglia (Paolicelli et al., 2011). A purely speculative function of TCR activation is the downregulation of $\alpha 7$ receptors during microglial pruning of neuronal dendritic spines. This may be a protective mechanism to decrease calcium influx through the highly calcium-permeable $\alpha 7$ receptors during the trauma of spine pruning.

TCR signaling through cell-cell contacts may also be necessary for the modulation of ion channel expression during formation of synapses. Cell-cell contact signaling may be formed when MHCI molecules from a presynaptic neuron bind to TCRs on the postsynaptic neuron. Evidence supporting the role of TCRMHCI complex in modulating neurotransmission includes the fact that MHCI-deficient mice display enhanced long-term potentiation in the hippocampus (Huh et al., 2000). Furthermore, $\mathrm{CD} 3 \zeta$ subunits were shown to modulate AMPA glutamatergic neurotransmission and dendritic development (Xu et al., 2010) in neurons of the retina.

nAChRs play an important role in affecting not only neuronal excitability but also synaptic plasticity in many CNS areas (Fujii et al., 2000; Ji et al., 2001; Couey et al., 2007). Our results show that $\alpha 7 \mathrm{nAChRs}$ contribute to neuronal excitability of cortical interneurons. Therefore, TCR inhibition of nAChR activity can dynamically and precisely tune the excitability of neurons. Because other ligand-gated ion channels, including $\mathrm{GABA}_{\mathrm{A}}$ (Wan et al., 1997), NMDA (Wang and Salter, 1994) and AMPA receptors (Ahmadian et al., 2004), can be functionally modulated by src tyrosine kinases, this opens the possibility that TCRs can modulate neuronal excitability by impacting the activity of many other ion channels in the CNS.

\section{References}

Ahmadian G, Ju W, Liu L, Wyszynski M, Lee SH, Dunah AW, Taghibiglou C, Wang Y, Lu J, Wong TP, Sheng M, Wang YT (2004) Tyrosine phosphorylation of GluR2 is required for insulin-stimulated AMPA receptor endocytosis and LTD. EMBO J 23:1040-1050. CrossRef Medline

Baudouin SJ, Angibaud J, Loussouarn G, Bonnamain V, Matsuura A, Kinebuchi M, Naveilhan P, Boudin H (2008) The signaling adaptor protein $\mathrm{CD} 3 \zeta$ is a negative regulator of dendrite development in young neurons. Mol Biol Cell 19:2444-2456. CrossRef Medline

Boulanger LM, Huh GS, Shatz CJ (2001) Neuronal plasticity and cellular immunity: shared molecular mechanisms. Curr Opin Neurobiol 11:568578. CrossRef Medline

Brown AM, Hope AG, Lambert JJ, Peters JA (1998) Ion permeation and conduction in a human recombinant 5-HT3 receptor subunit (h5HT3A). J Physiol 507:653-665. CrossRef Medline

Charpantier E, Wiesner A, Huh KH, Ogier R, Hoda JC, Allaman G, Raggenbass M, Feuerbach D, Bertrand D, Fuhrer C (2005) $\alpha 7$ neuronal nicotinic acetylcholine receptors are negatively regulated by tyrosine phosphorylation and Src-family kinases. J Neurosci 25:9836-9849. CrossRef Medline

Chen D, Patrick JW (1997) The $\alpha$-bungarotoxin-binding nicotinic acetylcholine receptor from rat brain contains only the $\alpha 7$ subunit. J Biol Chem 272:24024-24029. CrossRef Medline

Cho CH, Song W, Leitzell K, Teo E, Meleth AD, Quick MW, Lester RA (2005) Rapid upregulation of $\alpha 7$ nicotinic acetylcholine receptors by tyrosine dephosphorylation. J Neurosci 25:3712-3723. CrossRef Medline

Christophe E, Roebuck A, Staiger JF, Lavery DJ, Charpak S, Audinat E (2002) Two types of nicotinic receptors mediate an excitation of neocortical layer I interneurons. J Neurophysiol 88:1318-1327. Medline

Corriveau RA, Huh GS, Shatz CJ (1998) Regulation of class I MHC gene expression in the developing and mature CNS by neural activity. Neuron 21:505-520. CrossRef Medline

Couey JJ, Meredith RM, Spijker S, Poorthuis RB, Smit AB, Brussaard AB, Mansvelder HD (2007) Distributed network actions by nicotine increase the threshold for spike-timing-dependent plasticity in prefrontal cortex. Neuron 54:73-87. CrossRef Medline

Dau A, Komal P, Truong M, Morris G, Evans G, Nashmi R (2013) RIC-3 
differentially modulates $\alpha 4 \beta 2$ and $\alpha 7$ nicotinic receptor assembly, expression, and nicotine-induced receptor upregulation. BMC Neurosci 14:47. CrossRef Medline

Escande-Beillard N, Washburn L, Zekzer D, Wu ZP, Eitan S, Ivkovic S, Lu Y, Dang H, Middleton B, Bilousova TV, Yoshimura Y, Evans CJ, Joyce S, Tian J, Kaufman DL (2010) Neurons preferentially respond to selfMHC class I allele products regardless of peptide presented. J Immunol 184:816-823. CrossRef Medline

Fernandes CC, Pinto-Duarte A, Ribeiro JA, Sebastião AM (2008) Postsynaptic action of brain-derived neurotrophic factor attenuates $\alpha 7$ nicotinic acetylcholine receptor-mediated responses in hippocampal interneurons. J Neurosci 28:5611-5618. CrossRef Medline

Freedman R, Wetmore C, Strömberg I, Leonard S, Olson L (1993) $\alpha$-bungarotoxin binding to hippocampal interneurons: immunocytochemical characterization and effects on growth factor expression. J Neurosci 13:1965-1975. Medline

Fujii S, Ji Z, Sumikawa K (2000) Inactivation of $\alpha 7$ ACh receptors and activation of non- $\alpha 7 \mathrm{ACh}$ receptors both contribute to long term potentiation induction in the hippocampal CA1 region. Neurosci Lett 286: 134-138. CrossRef Medline

Gill CH, Peters JA, Lambert JJ (1995) An electrophysiological investigation of the properties of a murine recombinant 5-HT3 receptor stably expressed in HEK 293 cells. Br J Pharmacol 114:1211-1221. CrossRef Medline

Hales TG, Dunlop JI, Deeb TZ, Carland JE, Kelley SP, Lambert JJ, Peters JA (2006) Common determinants of single channel conductance within the large cytoplasmic loop of 5-hydroxytryptamine type 3 and $\alpha 4 \beta 2$ nicotinic acetylcholine receptors. J Biol Chem 281:8062-8071. CrossRef Medline

Huang Y, Wange RL (2004) T cell receptor signaling: beyond complex complexes. J Biol Chem 279:28827-28830. CrossRef Medline

Huh GS, Boulanger LM, Du H, Riquelme PA, Brotz TM, Shatz CJ (2000) Functional requirement for class I MHC in CNS development and plasticity. Science 290:2155-2159. CrossRef Medline

Irvine DJ, Purbhoo MA, Krogsgaard M, Davis MM (2002) Direct observation of ligand recognition by $\mathrm{T}$ cells. Nature 419:845-849. CrossRef Medline

Ji D, Lape R, Dani JA (2001) Timing and location of nicotinic activity enhances or depresses hippocampal synaptic plasticity. Neuron 31:131-141. CrossRef Medline

Komal P, Evans G, Nashmi R (2011) A rapid agonist application system for fast activation of ligand-gated ion channels. J Neurosci Methods 198:246254. CrossRef Medline

Lambert JJ, Peters JA, Hales TG, Dempster J (1989) The properties of 5-HT3 receptors in clonal cell lines studied by patch-clamp techniques. $\mathrm{Br} \mathrm{J}$ Pharmacol 97:27-40. CrossRef Medline

Lansdell SJ, Gee VJ, Harkness PC, Doward AI, Baker ER, Gibb AJ, Millar NS (2005) RIC-3 enhances functional expression of multiple nicotinic acetylcholine receptor subtypes in mammalian cells. Mol Pharmacol 68: 1431-1438. CrossRef Medline

Levin ED, McClernon FJ, Rezvani AH (2006) Nicotinic effects on cognitive function: behavioral characterization, pharmacological specification, and anatomic localization. Psychopharmacology (Berl) 184: 523-539. CrossRef Medline

Manders EMM, Verbeek FJ, Aten JA (1993) Measurement of colocalization of objects in dual-colour confocal images. J Microsc 169:375382. CrossRef

Nagai T, Ibata K, Park ES, Kubota M, Mikoshiba K, Miyawaki A (2002) A variant of yellow fluorescent protein with fast and efficient maturation for cell-biological applications. Nat Biotechnol 20:87-90. CrossRef Medline

Neumann H, Schmidt H, Cavalié A, Jenne D, Wekerle H (1997) Major histocompatibility complex (MHC) class I gene expression in single neurons of the central nervous system: differential regulation by interferon (IFN)gamma and tumor necrosis factor (TNF)- $\alpha$. J Exp Med 185:305-316. CrossRef Medline

Nitabach MN, Llamas DA, Thompson IJ, Collins KA, Holmes TC (2002) Phosphorylation-dependent and phosphorylation-independent modes of modulation of shaker family voltage-gated potassium channels by SRC family protein tyrosine kinases. J Neurosci 22:7913-7922. Medline

Ohashi PS, Mak TW, Van den Elsen P, Yanagi Y, Yoshikai Y, Calman AF, Terhorst C, Stobo JD, Weiss A (1985) Reconstitution of an active surface T3/T-cell antigen receptor by DNA transfer. Nature 316:606-609. CrossRef Medline

Palacios R (1982) Concanavalin A triggers T lymphocytes by directly inter- acting with their receptors for activation. J Immunol 128:337-342. Medline

Paolicelli RC, Bolasco G, Pagani F, Maggi L, Scianni M, Panzanelli P, Giustetto M, Ferreira TA, Guiducci E, Dumas L, Ragozzino D, Gross CT (2011) Synaptic pruning by microglia is necessary for normal brain development. Science 333:1456-1458. CrossRef Medline

Parsons SJ, Parsons JT (2004) Src family kinases, key regulators of signal transduction. Oncogene 23:7906-7909. CrossRef Medline

Poorthuis RB, Bloem B, Schak B, Wester J, de Kock CP, Mansvelder HD (2013) Layer-specific modulation of the prefrontal cortex by nicotinic acetylcholine receptors. Cereb Cortex 23:148-161. CrossRef Medline

Sallusto F, Impellizzieri D, Basso C, Laroni A, Uccelli A, Lanzavecchia A, Engelhardt B (2012) T-cell trafficking in the central nervous system. Immunol Rev 248:216-227. CrossRef Medline

Samelson LE, Phillips AF, Luong ET, Klausner RD (1990) Association of the fyn protein-tyrosine kinase with the T-cell antigen receptor. Proc Natl Acad Sci U S A 87:4358-4362. CrossRef Medline

Shaw AS, Amrein KE, Hammond C, Stern DF, Sefton BM, Rose JK (1989) The lck tyrosine protein kinase interacts with the cytoplasmic tail of the CD4 glycoprotein through its unique N-terminal domain. Cell 59:627636. CrossRef Medline

Shaw G, Morse S, Ararat M, Graham FL (2002) Preferential transformation of human neuronal cells by human adenoviruses and the origin of HEK 293 cells. FASEB J 16:869-871. CrossRef Medline

Sigworth FJ (1980) The variance of sodium current fluctuations at the node of Ranvier. J Physiol 307:97-129. Medline

Sigworth FJ (1981) Interpreting power spectra from nonstationary membrane current fluctuations. Biophys J 35:289-300. CrossRef Medline

Syken J, Shatz CJ (2003) Expression of T cell receptor $\beta$ locus in central nervous system neurons. Proc Natl Acad Sci U S A 100:13048-13053. CrossRef Medline

Tooyama I, Kimura H, Akiyama H, McGeer PL (1990) Reactive microglia express class I and class II major histocompatibility complex antigens in Alzheimer's disease. Brain Res 523:273-280. CrossRef Medline

von Engelhardt J, Eliava M, Meyer AH, Rozov A, Monyer H (2007) Functional characterization of intrinsic cholinergic interneurons in the cortex. J Neurosci 27:5633-5642. CrossRef Medline

Wan Q, Man HY, Braunton J, Wang W, Salter MW, Becker L, Wang YT (1997) Modulation of GABAA receptor function by tyrosine phosphorylation of $\beta$ subunits. J Neurosci 17:5062-5069. Medline

Wang YT, Salter MW (1994) Regulation of NMDA receptors by tyrosine kinases and phosphatases. Nature 369:233-235. CrossRef Medline

Weiss A, Littman DR (1994) Signal transduction by lymphocyte antigen receptors. Cell 76:263-274. CrossRef Medline

Weiss A, Chan AC, Iwashima M, Straus D, Irving BA (1992) Regulation of protein tyrosine kinase activation by the T-cell antigen receptor $\zeta$ chain. Cold Spring Harb Symp Quant Biol 57:107-116. CrossRef Medline

Winer JA, Larue DT (1989) Populations of GABAergic neurons and axons in layer I of rat auditory cortex. Neuroscience 33:499-515. CrossRef Medline

Xu HP, Chen H, Ding Q, Xie ZH, Chen L, Diao L, Wang P, Gan L, Crair MC, Tian N (2010) The immune protein $\mathrm{CD} 3 \zeta$ is required for normal development of neural circuits in the retina. Neuron 65:503-515. CrossRef Medline

Young JW, Crawford N, Kelly JS, Kerr LE, Marston HM, Spratt C, Finlayson $\mathrm{K}$, Sharkey J (2007) Impaired attention is central to the cognitive deficits observed in $\alpha 7$ deficient mice. Eur Neuropsychopharmacol 17:145-155. CrossRef Medline

Yutani K, Ogasahara K, Tsujita T, Sugino Y (1987) Dependence of conformational stability on hydrophobicity of the amino acid residue in a series of variant proteins substituted at a unique position of tryptophan synthase $\alpha$ subunit. Proc Natl Acad Sci U S A 84:4441-4444. CrossRef Medline

Zhang H, Garlichs CD, Mügge A, Daniel WG (1998) Involvement of tyrosine kinases, $\mathrm{Ca}^{2+}$ and PKC in activation of mitogen-activated protein (MAP) kinase in human polymorphonuclear neutrophils. J Physiol 513: 359-367. CrossRef Medline

Zhou X, Nai Q, Chen M, Dittus JD, Howard MJ, Margiotta JF (2004) Brainderived neurotrophic factor and trkB signaling in parasympathetic neurons: relevance to regulating $\alpha 7$-containing nicotinic receptors and synaptic function. J Neurosci 24:4340-4350. CrossRef Medline 